\title{
TIME AS A TRIBUTARY OF ARCHITECTURAL WORK
}

\author{
Haby Hosney Mostafa Ahmed \\ Architecture Department, Faculty of Fine Arts in Cairo, Helwan University, Cairo, Egypt \\ E-mail: habyhosney@gmail.com
}

\begin{abstract}
The concept of time in architecture remains a questionable path in the absence of an agreed interpretation of the term of time itself. Time is the most ambiguous element in the realization of architectural work, although it has been reached out that there are two types of time: One of them is tangible, has units of measurements, which is the lived time, the other is a personal time can be easily moved through, where you can call the past and move towards the future, so according to this, time becomes an influential element in the process of imagination, one of the components of the creative process of the designer. It is the most prominent in feelings and ideas which is expended to stimulate the visual memory of the recipient of the architectural work. This turns in the framework of the culture of both: the designer and the recipient. Time in architecture is materially intangible but it is tangible sensibly and morally. If used as a design tool requires to monitor and adopt a clear philosophy before it appears to the user. Time in the contemporary architecture varies between the present time, "the time of stability": represents the reality of work and the symbol of stability, which is a continuous time break out of the realization of the work, and the "time of retrieval", which uses the symbol and linked to the identity or distinctive character, the future time "time of aspiration" refers to the aspiration and motivation to the "spatial experience". The temporal experience is the "rarefaction time". The rarefaction introduces a new dimension, unpredictable and rarefacted time contribute to the creation of self-contained worlds to the viewer and receiver. "Social time" is the consciousness of the human being itself and the recognition of its value as a junction or corner of Time and Place relationship required by action Embodied in the required social activities that are part of the design of the architectural work and increase the integration between the recipient and work.
\end{abstract}

Time in contemporary architecture was associated with the movement where synchronization and multiple views in one building according to different points of view resulting from a composite form.

KEY WORDS: Time , Contemporary Architecture , Cognition, Movement , Designed Time

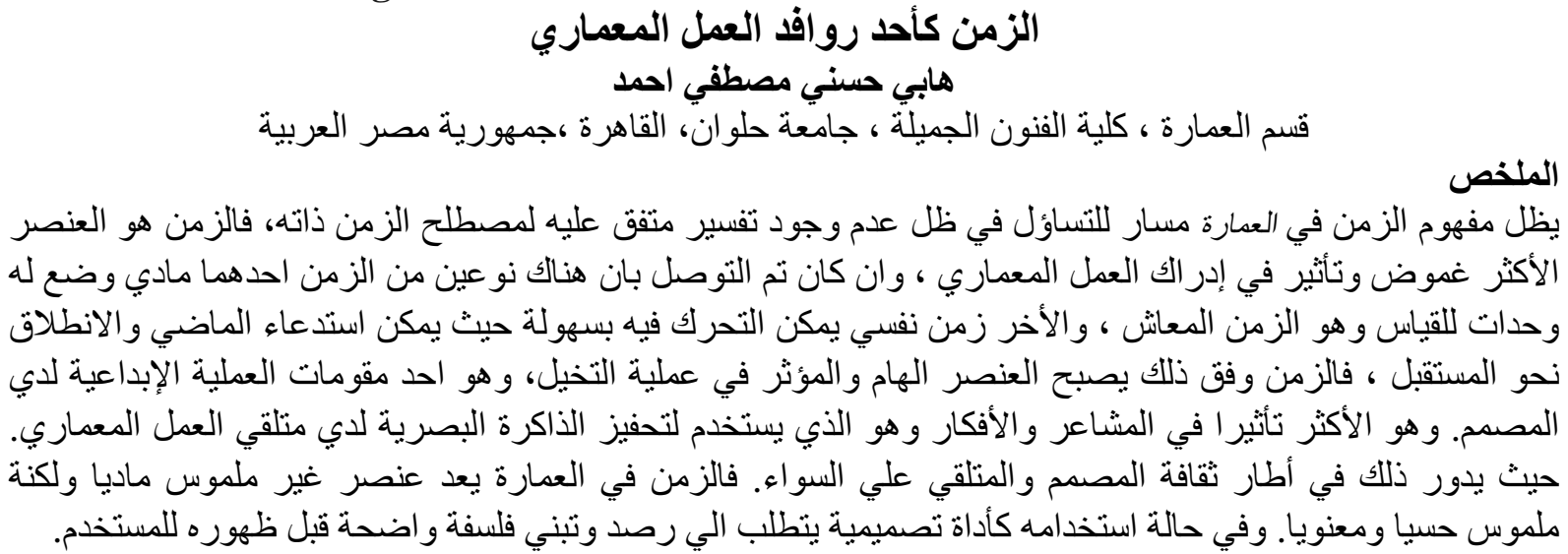




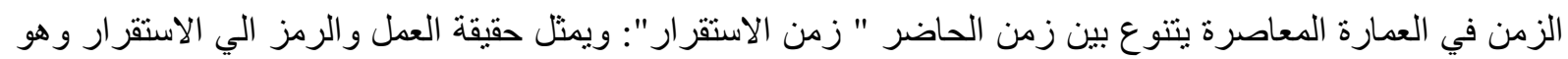

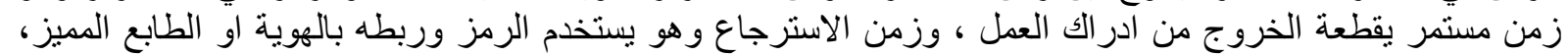

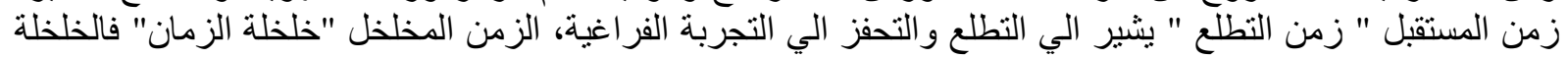

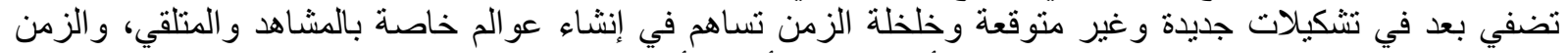

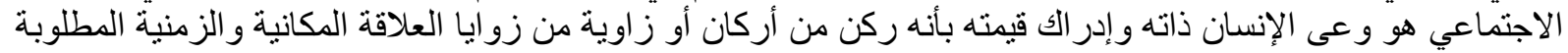

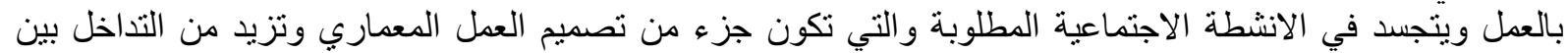

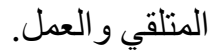
الزمن في العمارة المعاصرة ارتبط بالحركة حيث التزامن وتعدد المناظر بالمبني الواحدوفق نقاط النظر المختلفة مما ينتج من شكل مركب. الكلمات المفتاحية: الزمن ـ العمارة المعاصرة ـ الإدراك ـ الحركة ــ الزمن المصمم هل اللزؤ البحني:

الإشكالية البحثية: مأ هي محددات التصميم: وفق الزمن الزمن في العمارة. فرضية البحث: ورؤى مختلفة، كأحد عناصر العملية الإبداعية في التصميم المعماري، بولئه

- - إلقاء الضوء علي الزمن كمفهوم تصميمي في العمارة المعاصرة. هدف البحث:

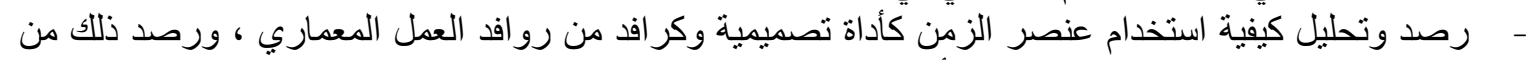

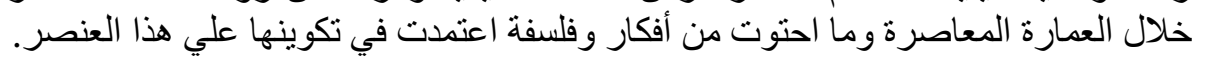

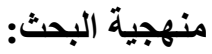

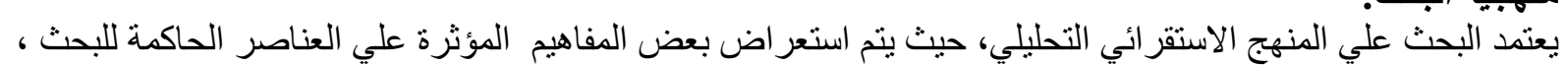

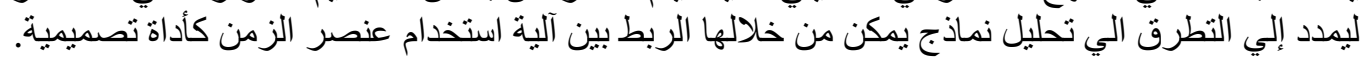

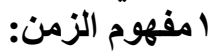

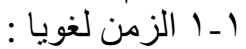

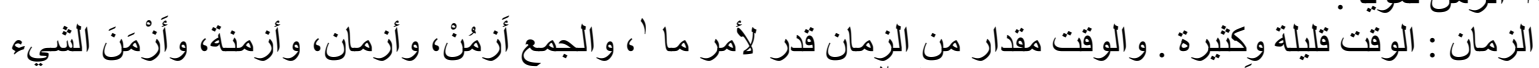

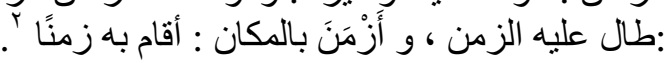

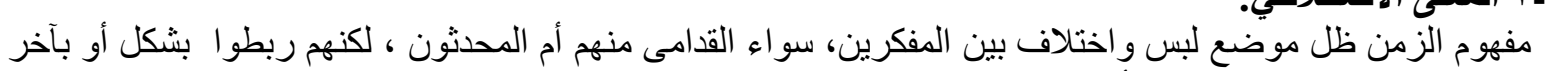

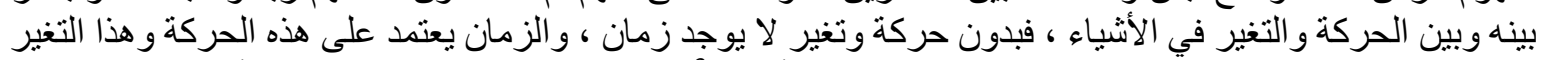

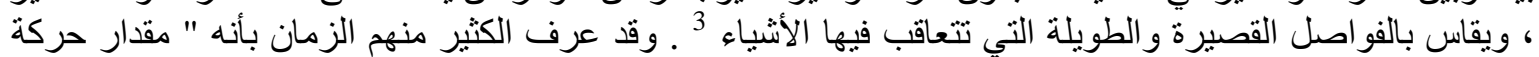

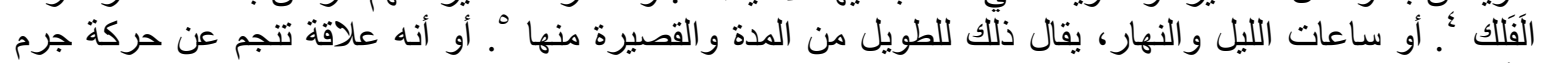

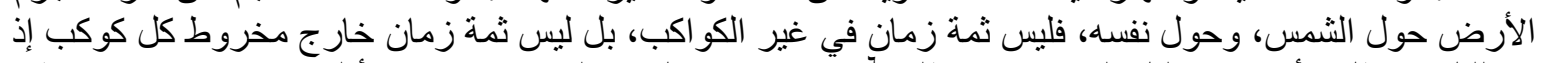

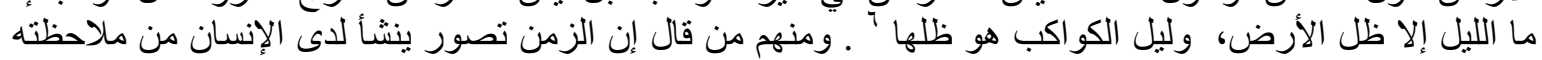
للتغير ات في الأشياء سو اءً كانت حركية أم كيفية.

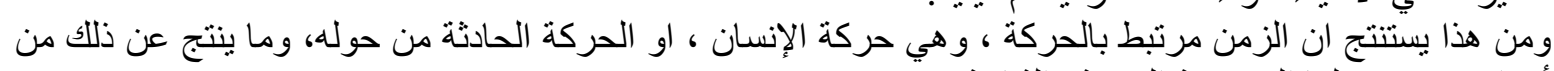
أحداث ودلالات لها المرجعية الحسية و الثنقافية.

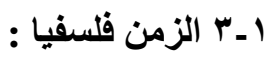

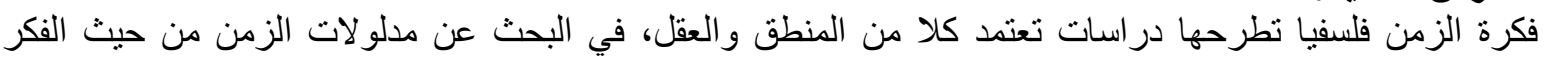

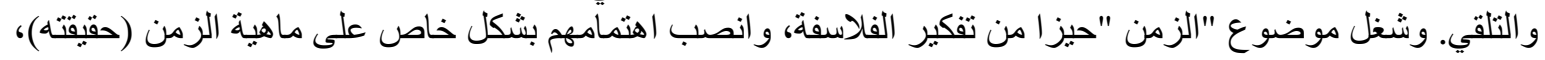




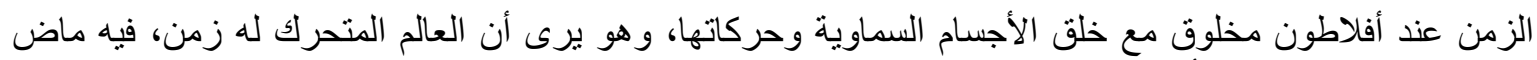

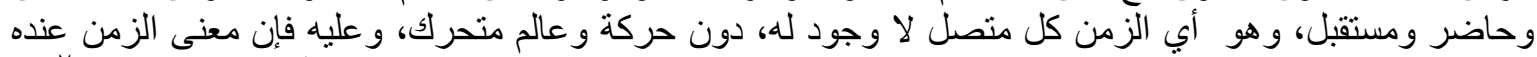

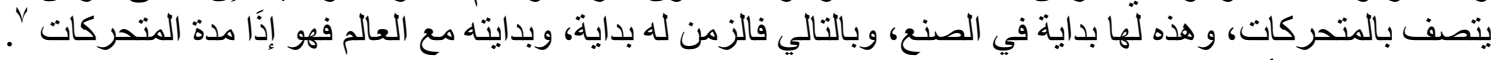

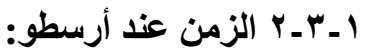

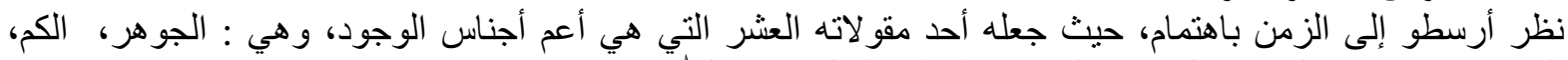

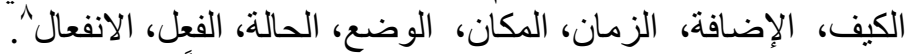

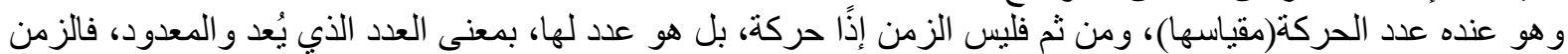

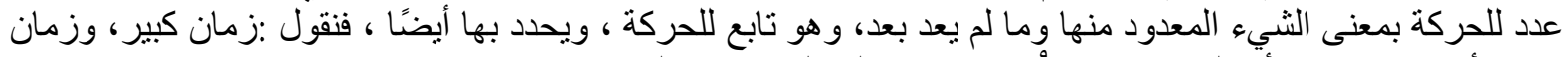

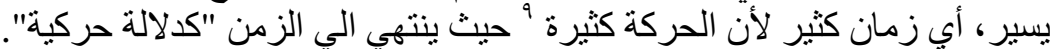
وليس للزمان عنده بداية و لا نهاية، لأن الزمان يرند إلى الآن، و الآن زمن مضىى، وبداية زمن مستقبل، فقبله زمان وبعده

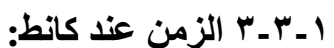

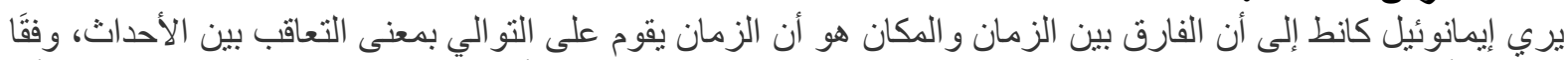

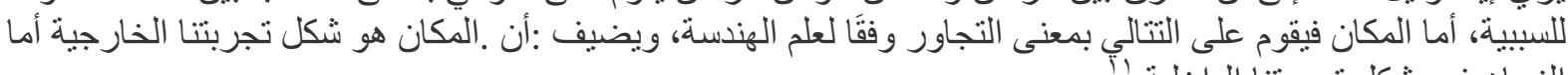

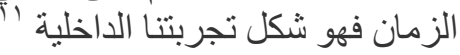

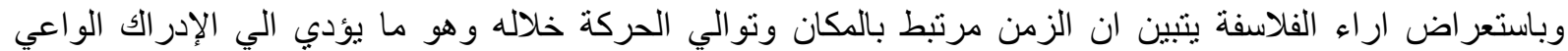

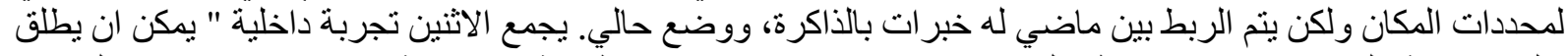
عليها تجربة التعايش" و هي مرتبط بالمكان وما يتضمنه من عناصر طبيعية وصناعية من صنع الإنسان كالعمران

و المباني.

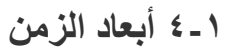

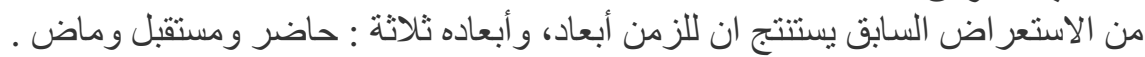

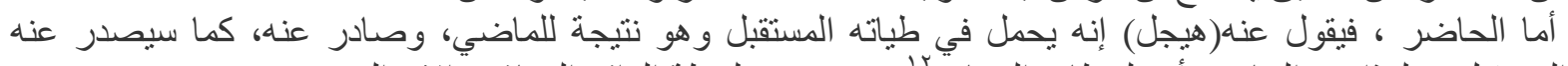

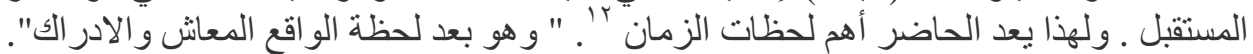

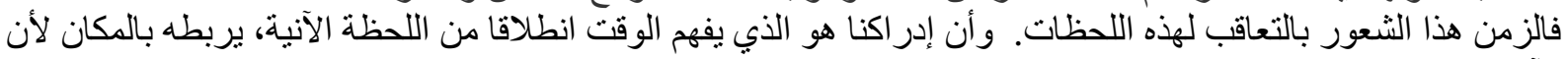

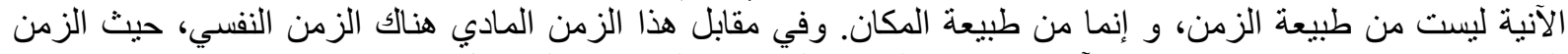

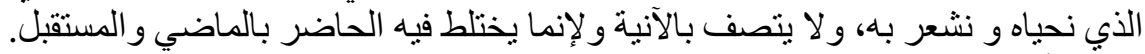

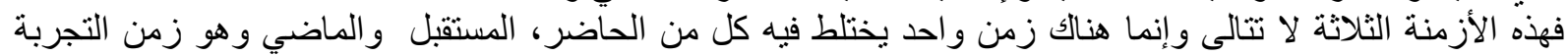
الحسية والنفسية، هذا هو الزمن قبل أن يتصرف فئه فئ ذكاؤناو يفككه إلى لحظات منمايزة.

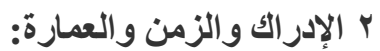
اكتشاف الإنسان لمرور الزمن علامدة كبري علي تطور العقل الإنساني وعلي نمو قدر اته وملكاته الإدر اكية ، حيث الوعي

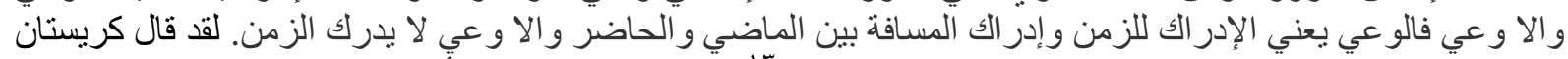

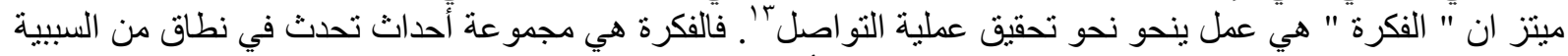

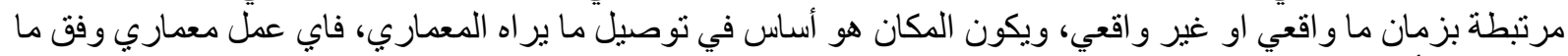

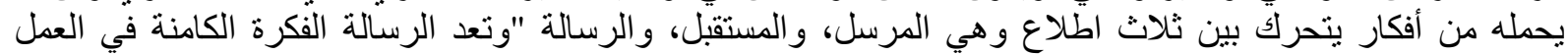

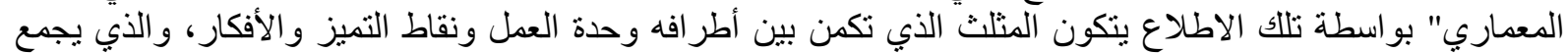

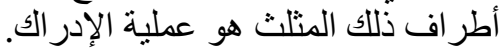

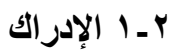

تعرف البيولوجيا ان لكل كائن حي جهازي استقبال الأول لتلقي المؤثر الخارجي، و الجهاز الثاني هو خاص بردئ التردود الأفعال

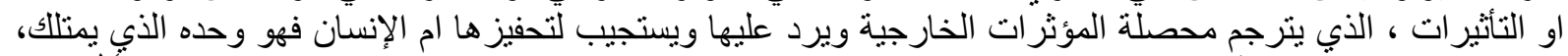

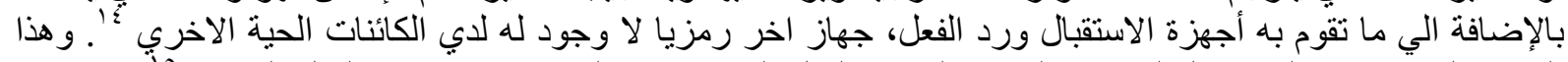

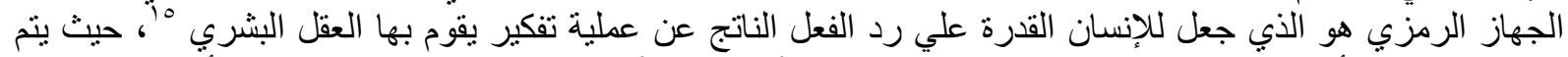

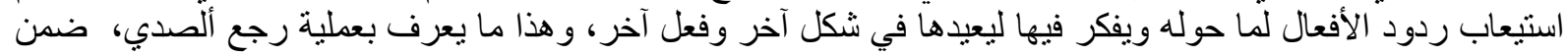

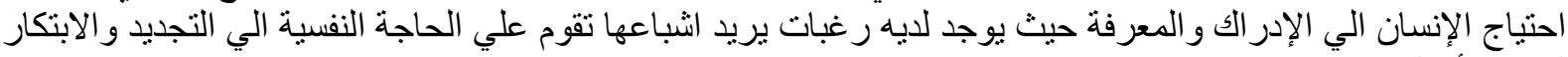

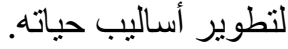




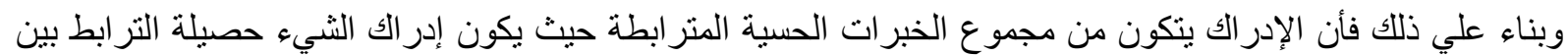

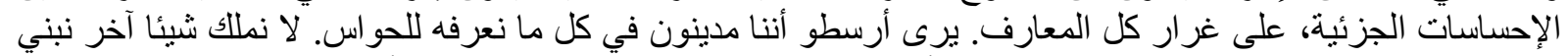

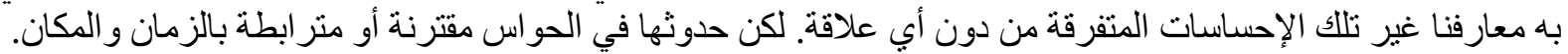

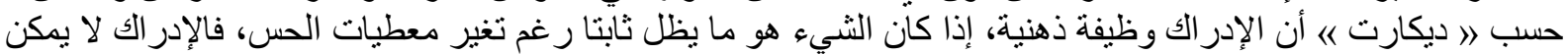

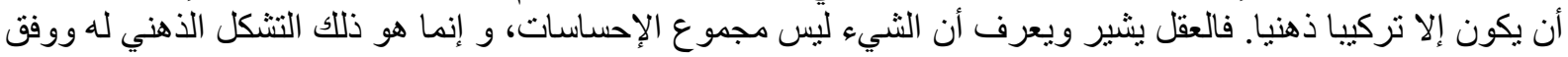

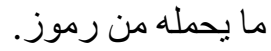

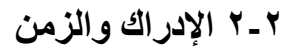

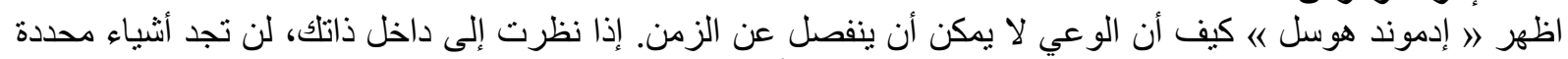

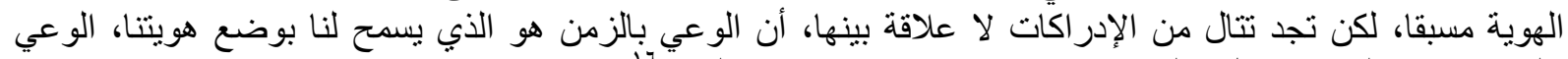

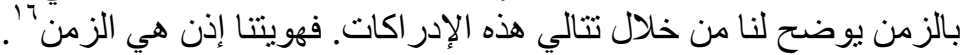

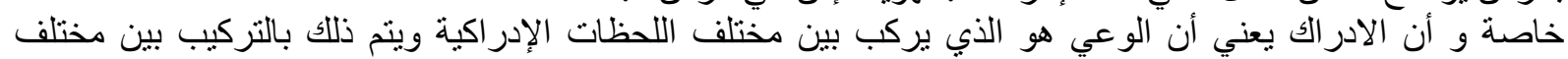

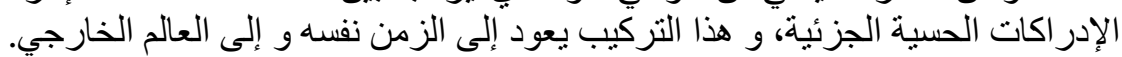

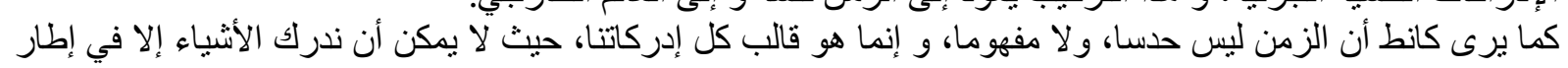

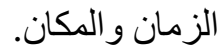

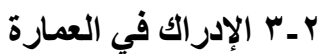

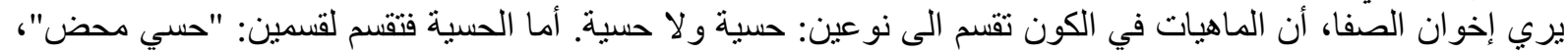

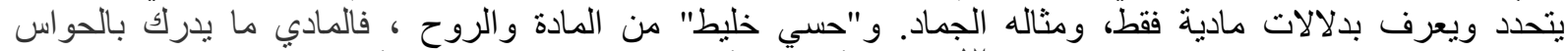

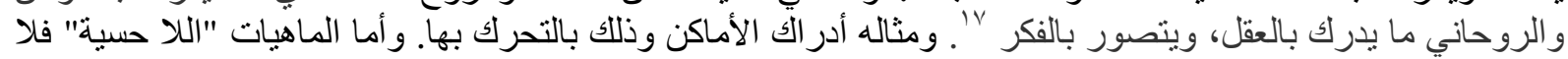
يمكن رصدها إنما يمكن تبين آثار ها، و غالبها يتحدد بدلالة الحسيات، ومثالها ضوء الثاليات الثمس أو الظل أو أدر الك حدود الحيز الفر اغي. وضمن هذا الإطار يناقش (Bill Hillier) أن الفراغ أو الحيز الفراغي هو موجود بالجدران المحيطة وبدونها. وهذه

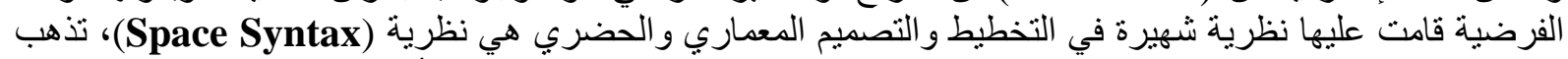

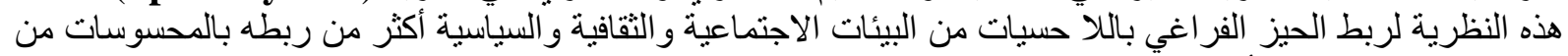

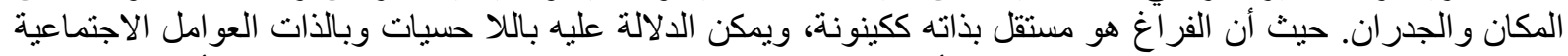

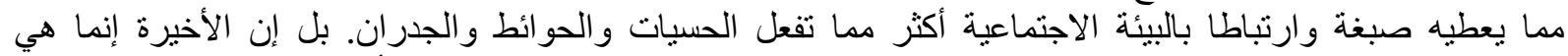

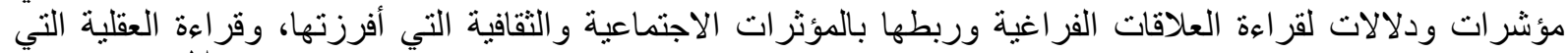

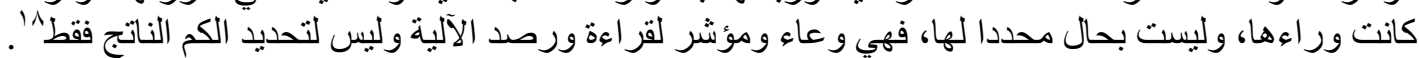

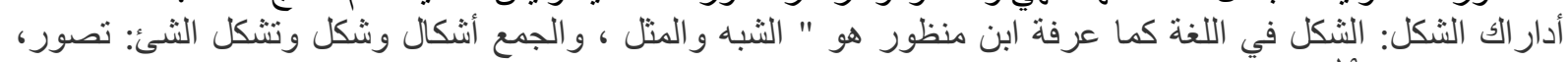

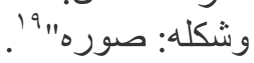

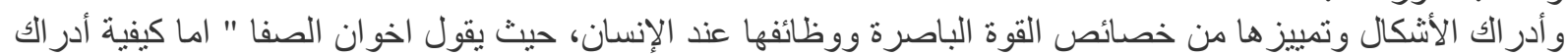

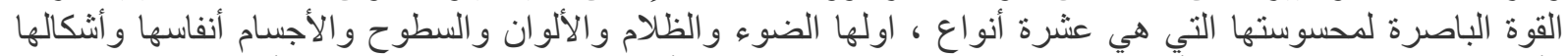

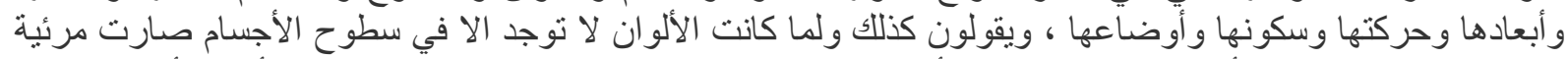

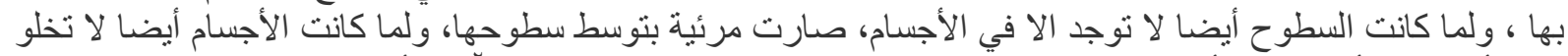

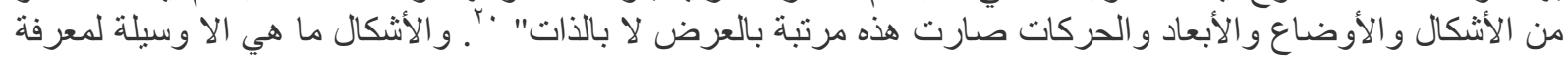

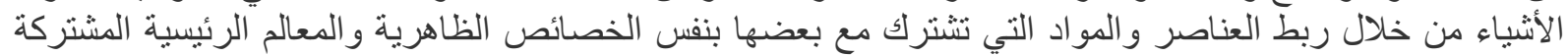

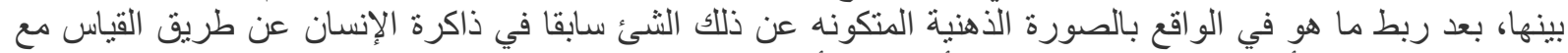

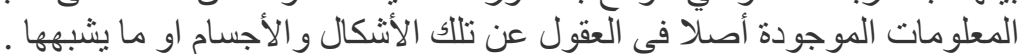

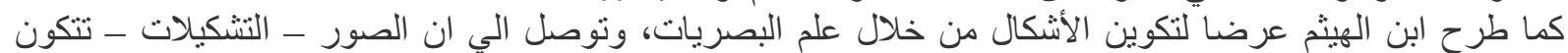

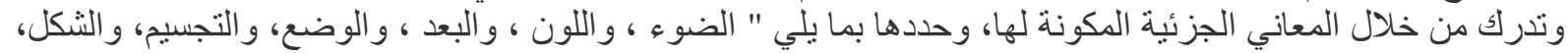

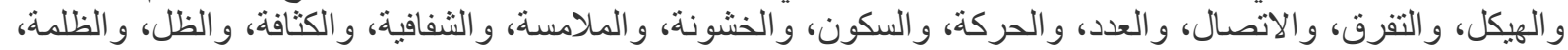

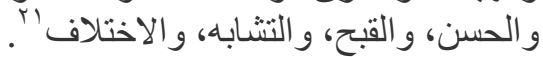

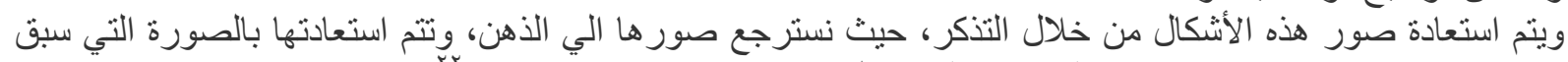

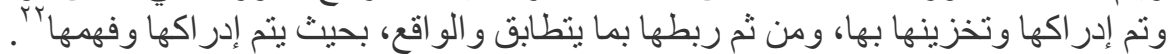

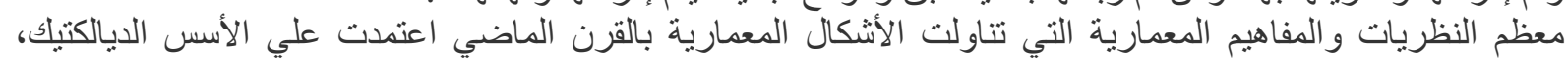

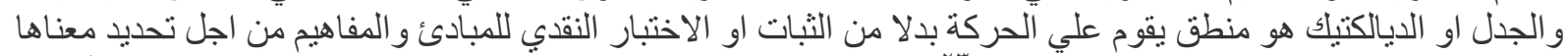

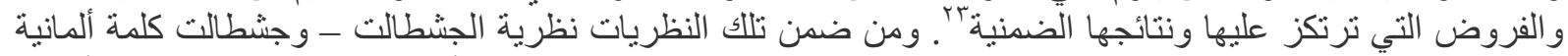
تعني الثكل او النمط او الصبغة، و هي الكل الكتكامل وليس مجرد مجموع للوحدات و الأجز اء. وفي علم النفس تعني أدر الك 


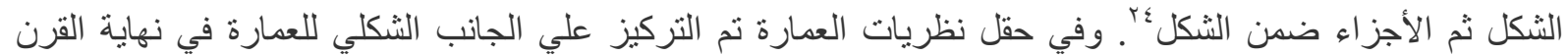

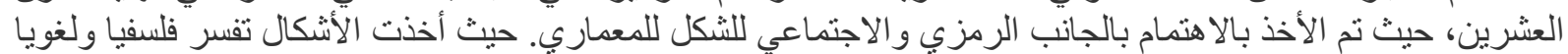

كما للخبرة دورا مهما في عملية الإدراك، او ما بسمي بالنمو الإدراكي، حيث ان النمو الإدراكي هو عملية تحصل

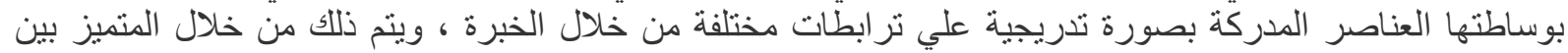

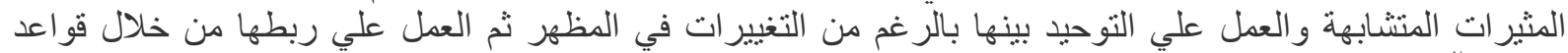

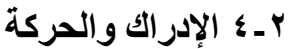
تتعاعقب الأحداث ويتغير الحدث، عن طريق نقاثلات مكانية وزمانية من خلال تحريك داخلي وفعل حركة مؤثرة علي أساس

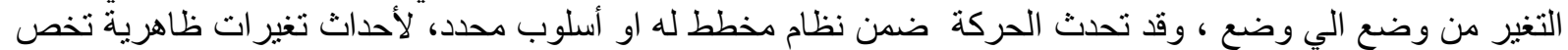

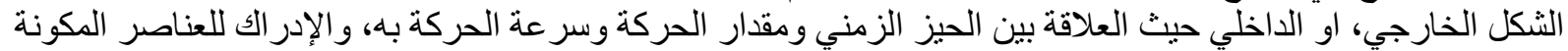

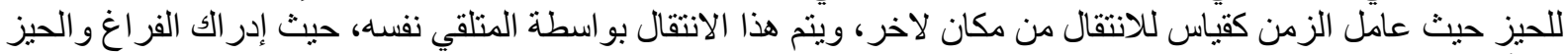

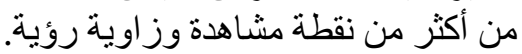

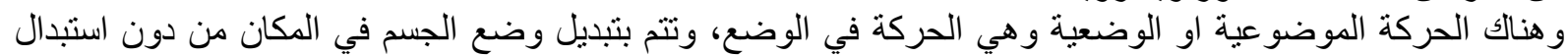

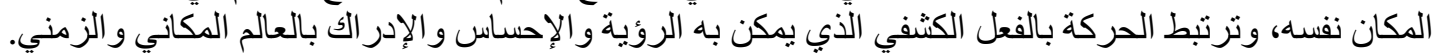

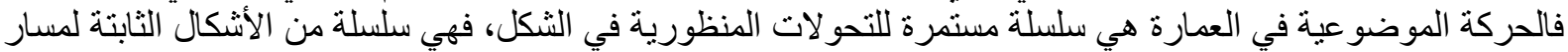
الزمن، وبذلك فان نتيجة الحركة تحدث تغير ات تطر اء علي إدر الك الثكل تؤدي الي إدر الك قر اءعات تصورية مختلفة.

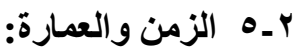
يري نيوتن ، ان الزمن والعمارة طرف ابدي في ثنائه مطلقة مع المكان او انه طرف في رباعية أطر افها الأخرى " المادة و الحركة

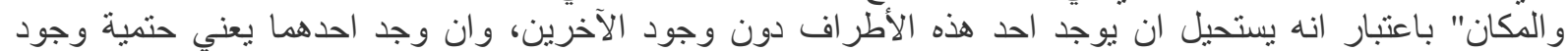

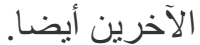

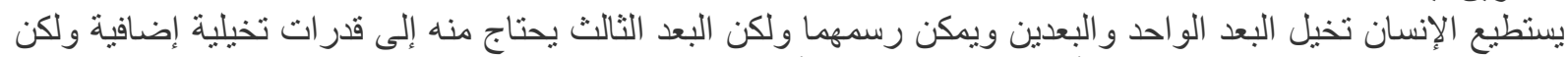

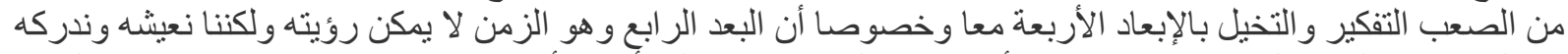

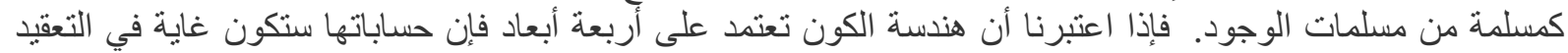

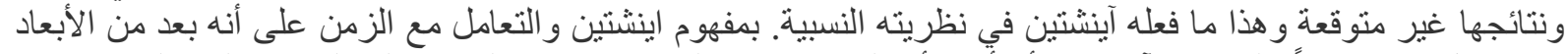

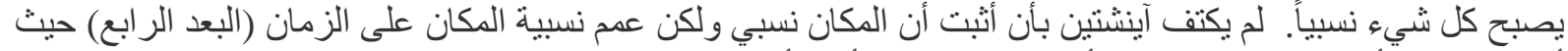

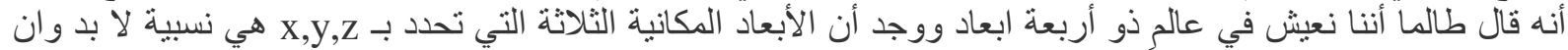

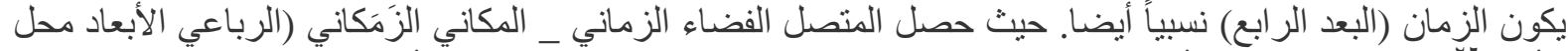

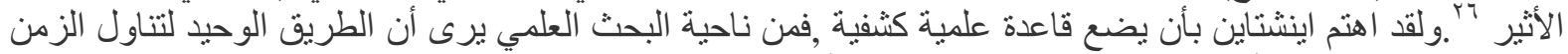

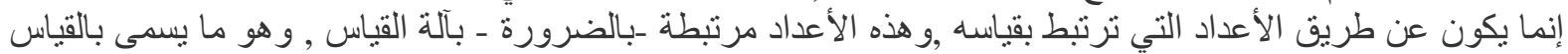

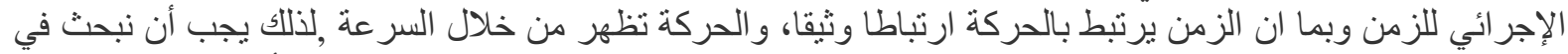

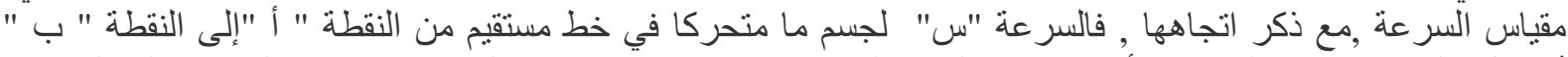

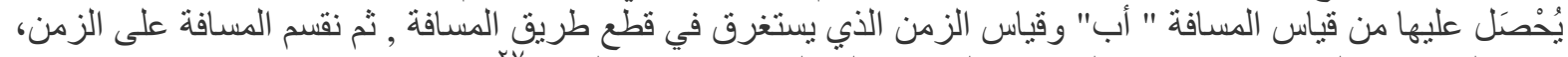

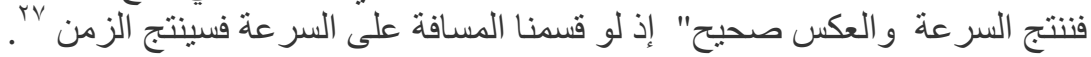

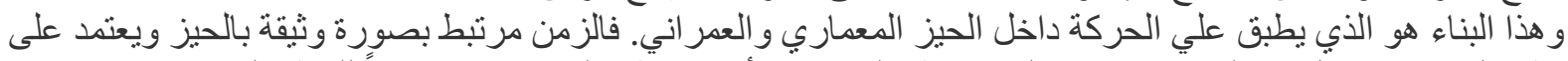

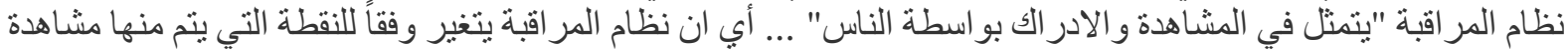

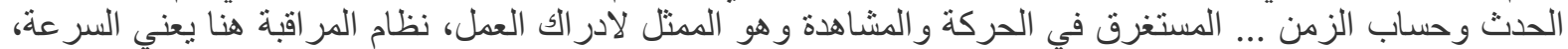

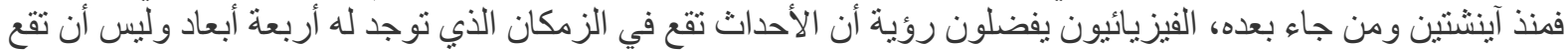
في نقطة ما من الزمن فقط.

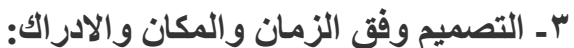

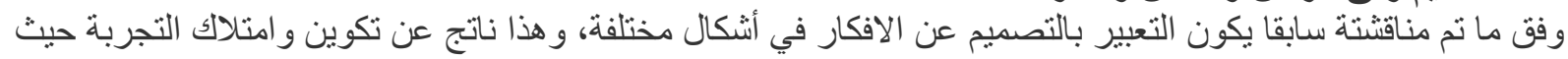

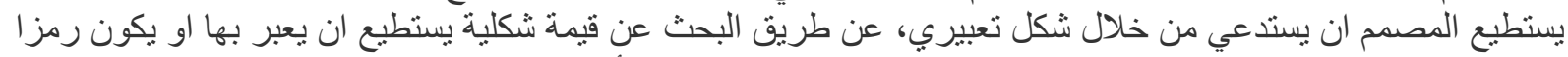

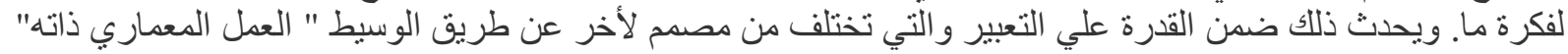

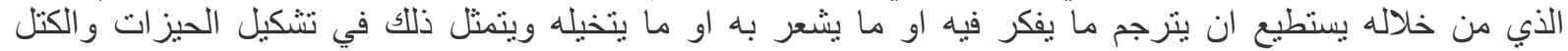

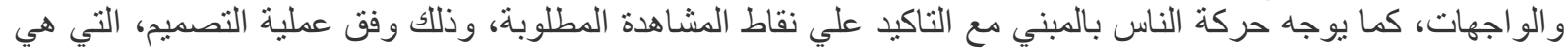




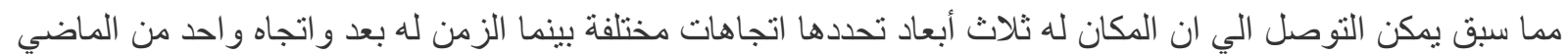

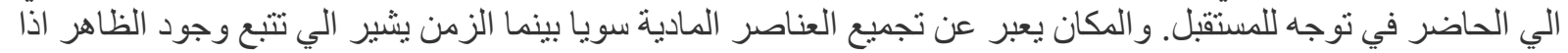

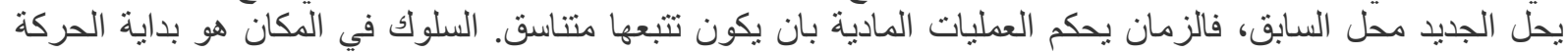

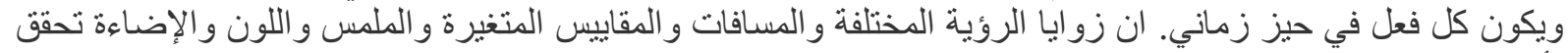

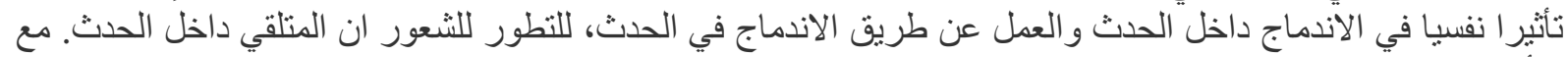

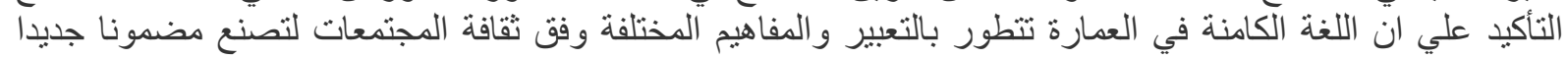
للقو اعد اللغوية في العمارة تختلف من ثقافة الي اخري.

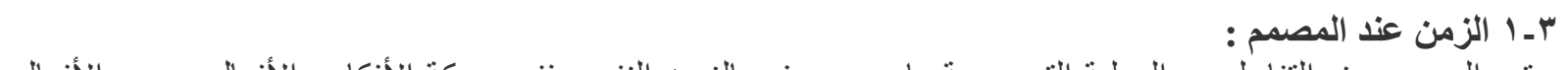
يعتمد المصمم عند التفاعل مع العملية التصميمية ما هو معرف بالزمن التمن النفسي ففي حركة الأفكار و الأفعال وردود الأفعال

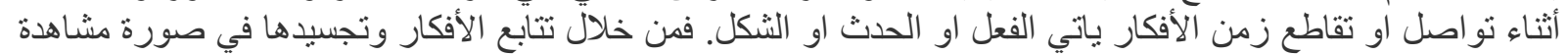

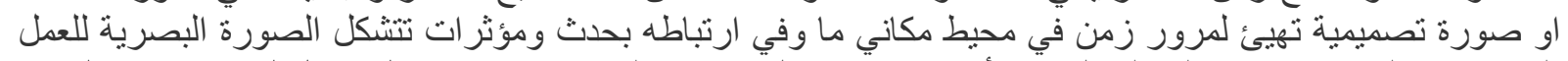

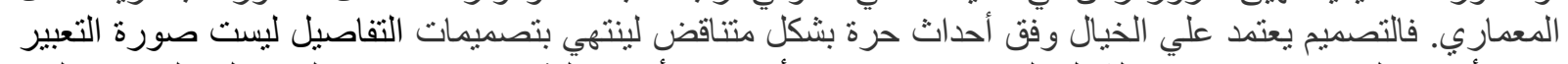

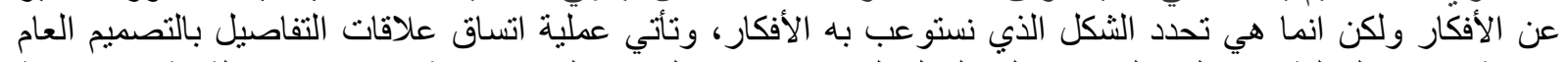

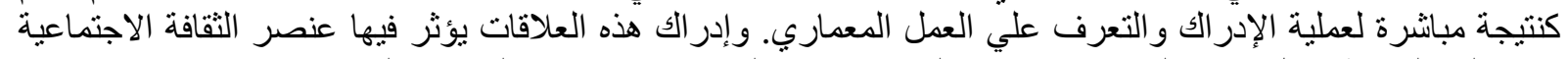

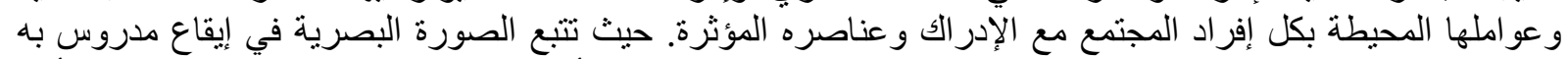

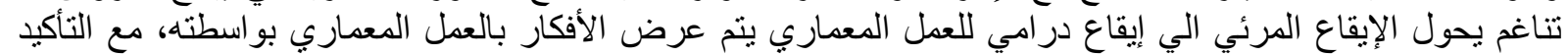

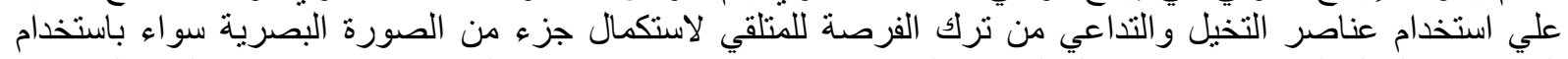

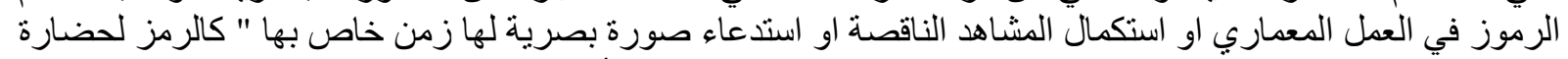

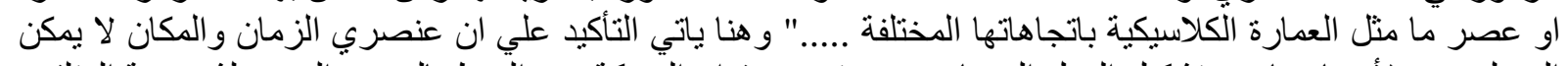

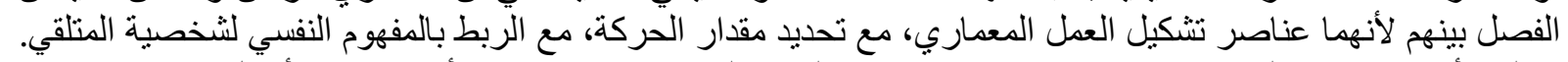

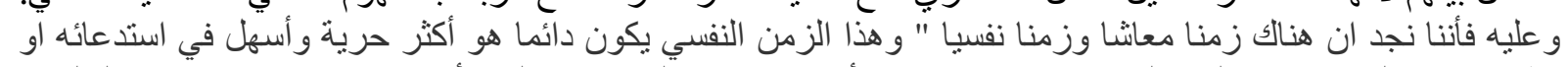

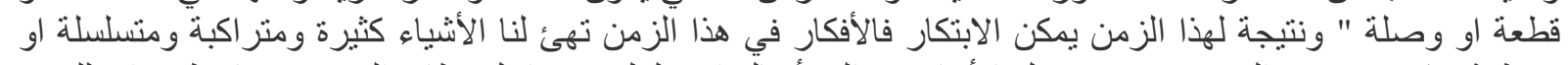

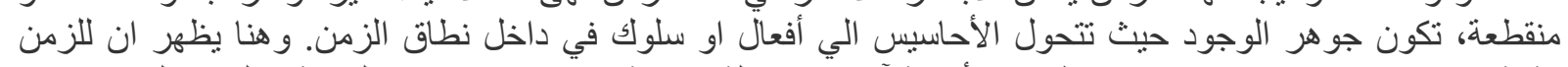

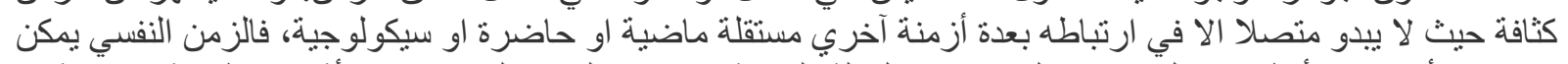

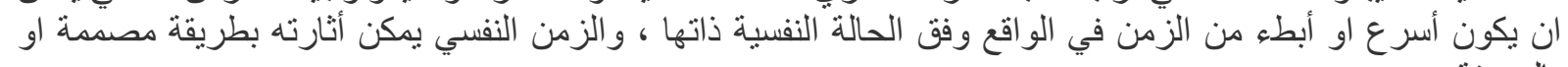
بالصدفة.

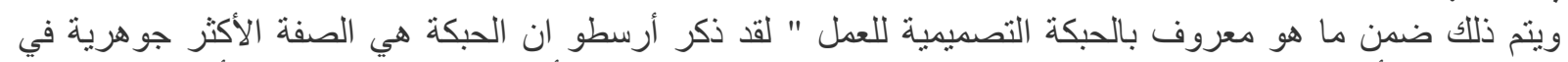

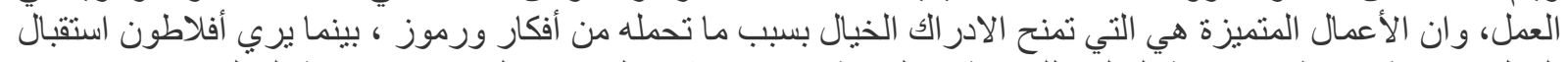

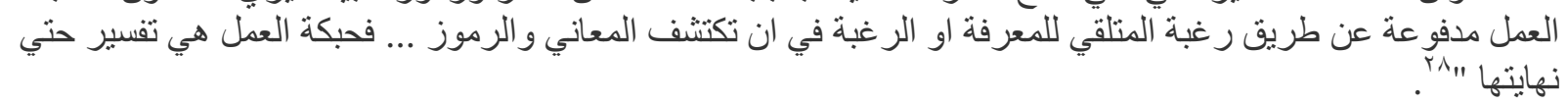

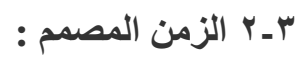 الزمن المصمم يعد الزّمن المنمثل في محددات التصميم والذي يمكن ان يتم تقسيمة وفق الاستتناج الي:}

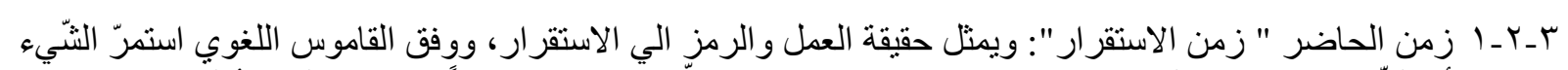

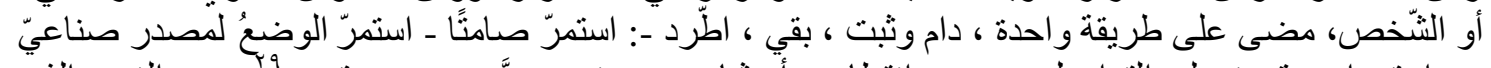

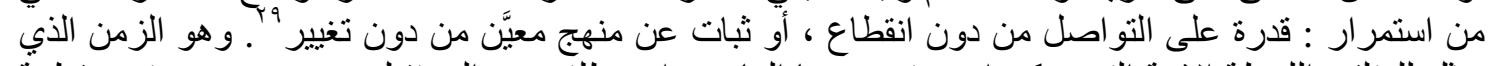

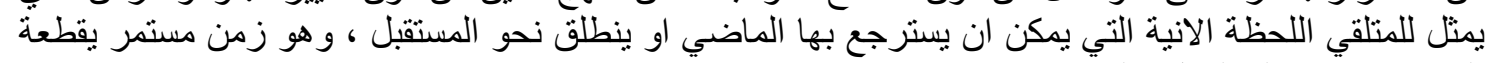

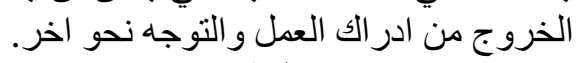

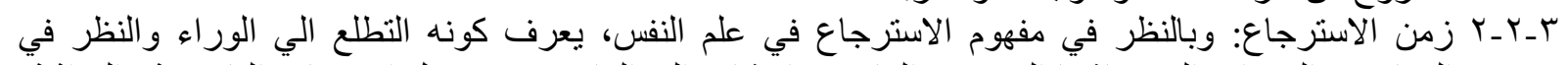

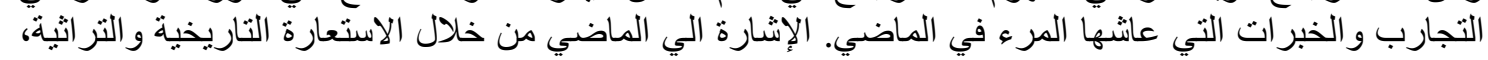

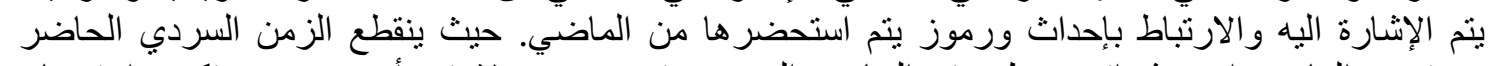

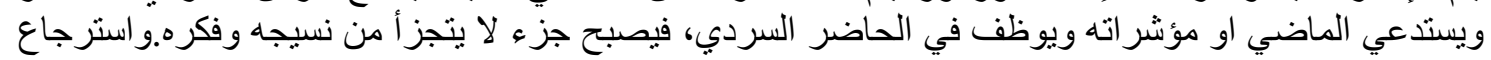

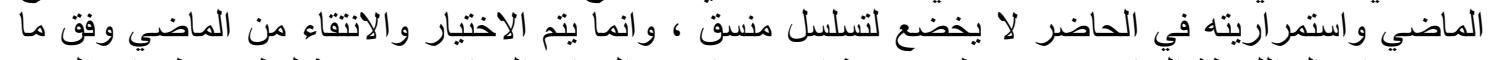

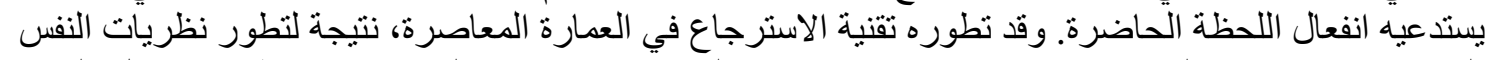

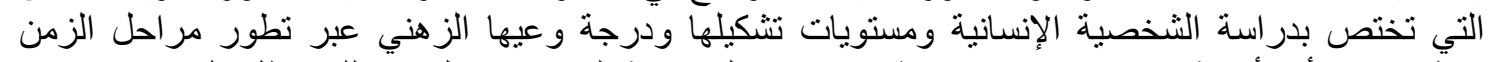

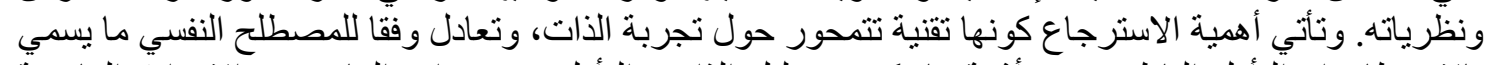

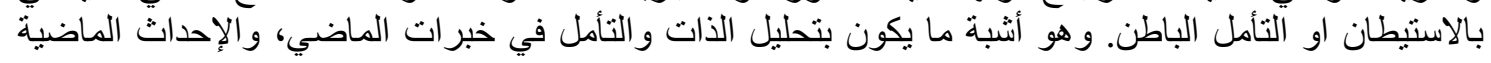




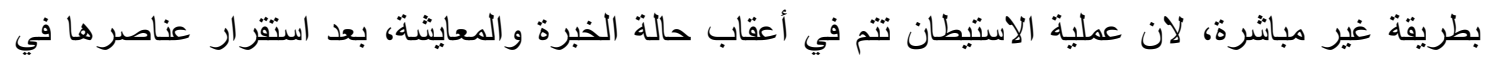

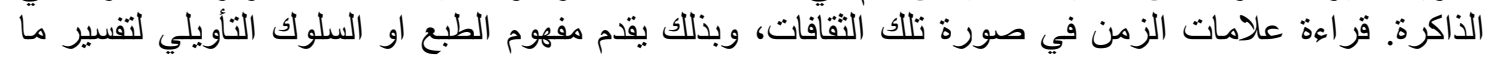

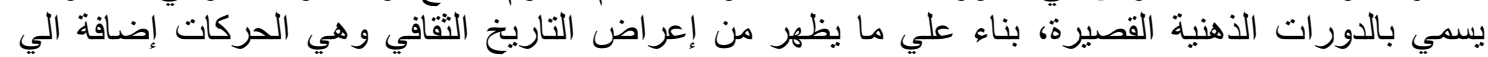

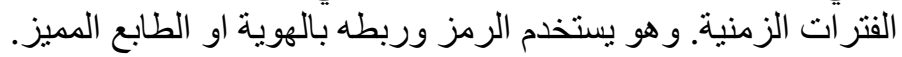

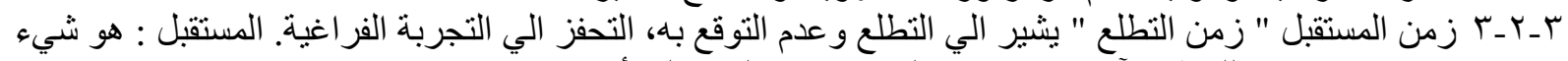

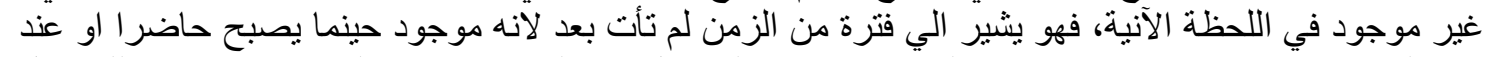

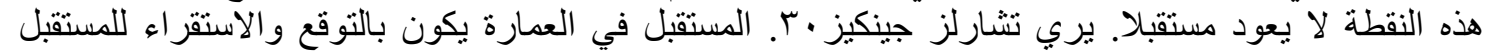

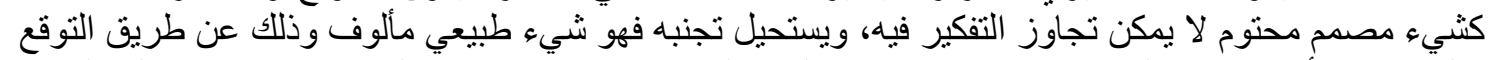

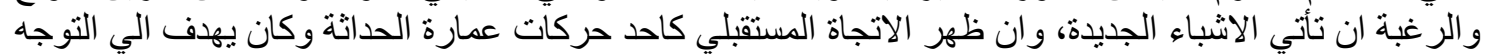

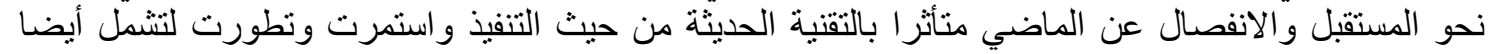

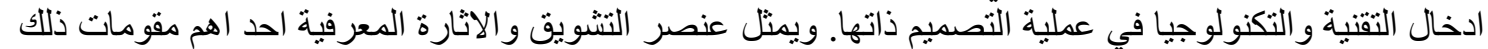

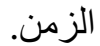

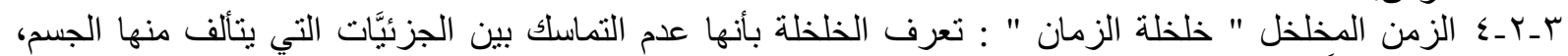

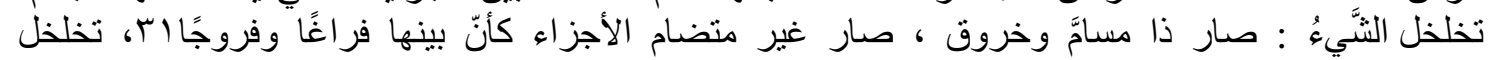

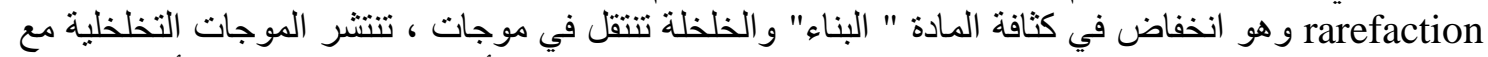

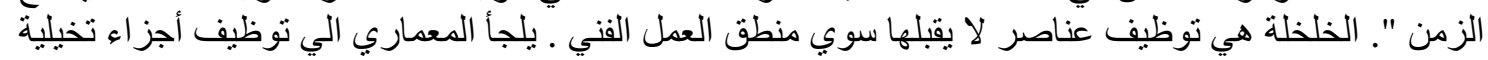

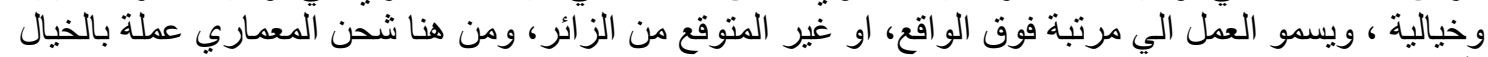

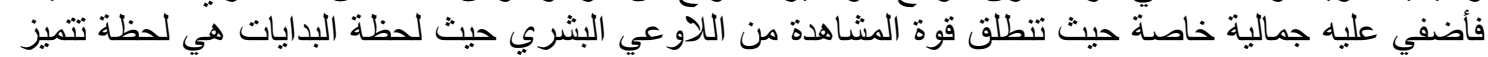
بالغموض. فالخلخلة تضفي بعد في تشكيلات جديدة وغير منوقة المقة. خلخلة الزمن تساهم في إنشاء عو الم خاصة بالمشاهد و المتلقي.

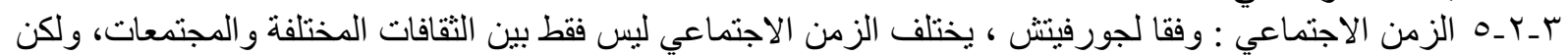

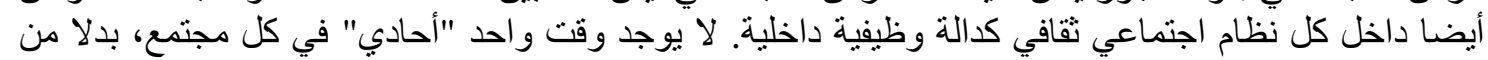

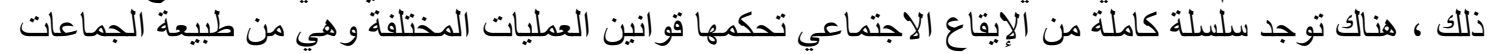

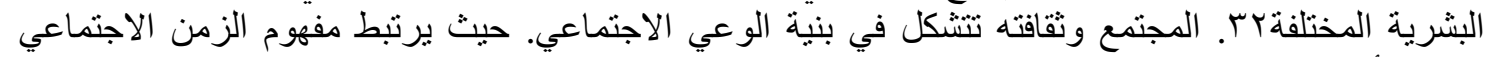

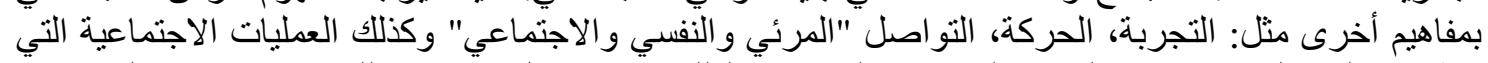

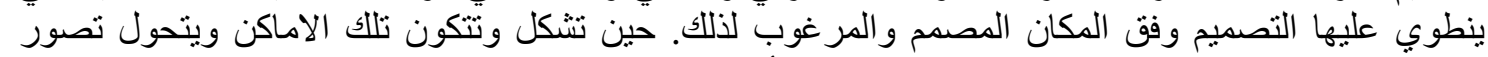

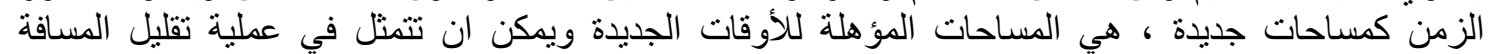

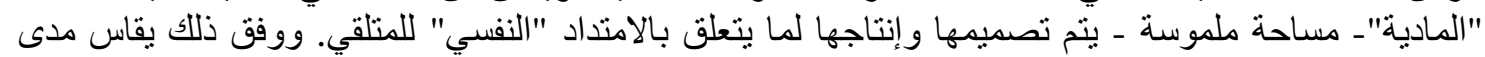

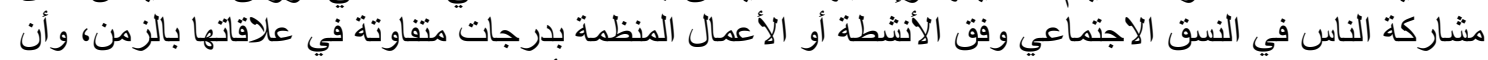

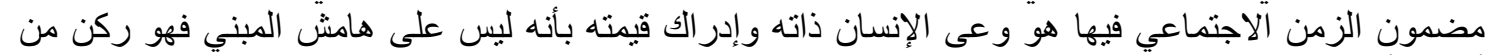

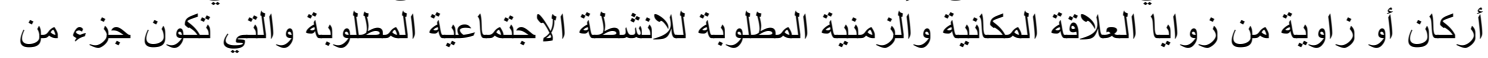

تصميم العمل المعماري.

عـ الزمن في العمارة المعاصرة:

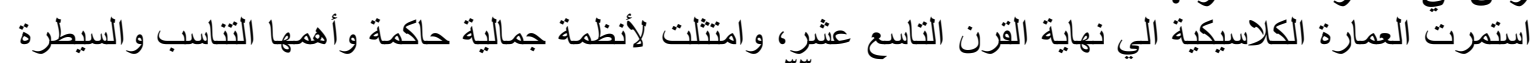

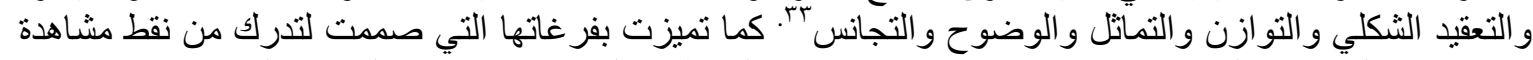

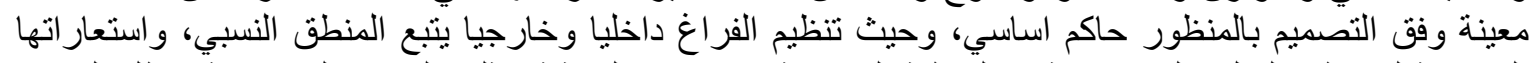

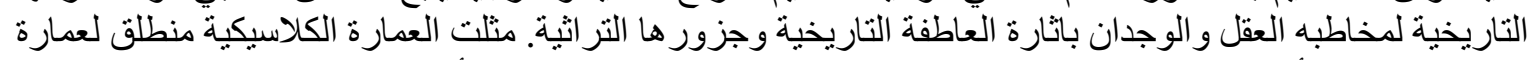

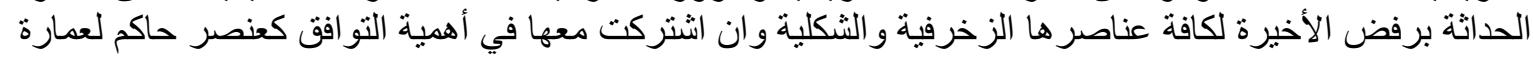

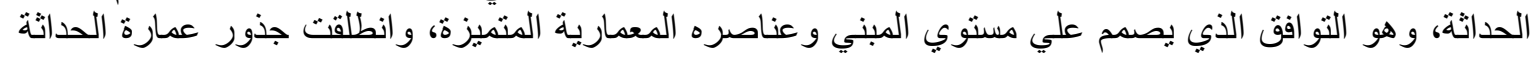

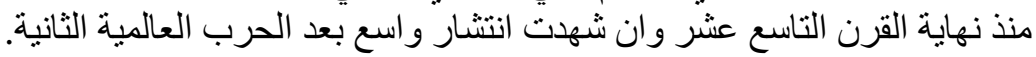

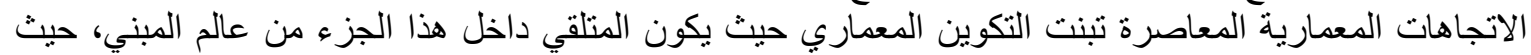

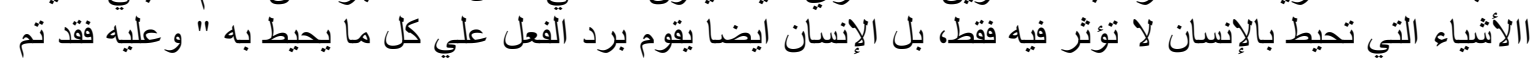

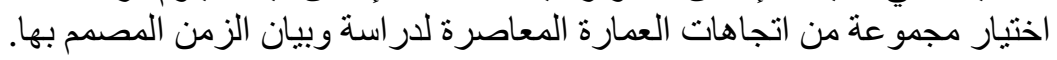

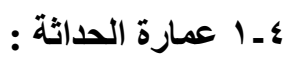

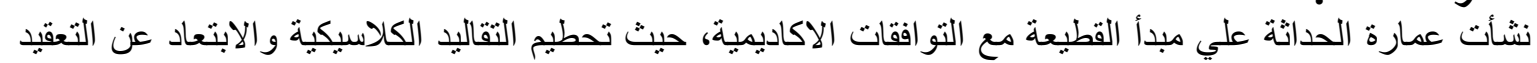

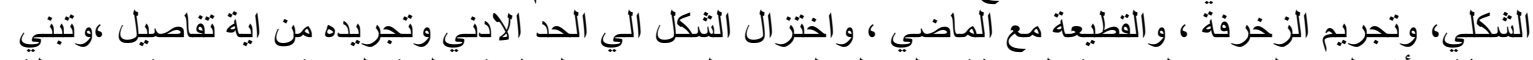
بساطة الأشكال، و الحجوم الهندسية البسيطة والجمال المبني علي تحقيق الوظيفة وتلبية النفعية الاجنماعية، وسهولة التئة 
ووضوح الإدراك لعناصر المبني الداخلية والخارجية والتواصل بين الداخل والخارج. و التطور التقني الحاكم في

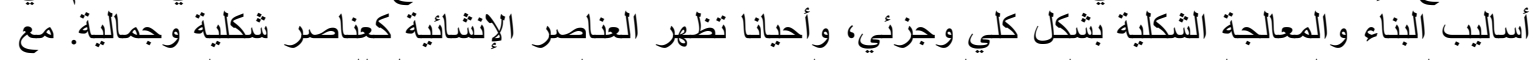

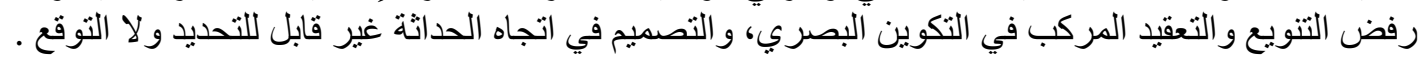

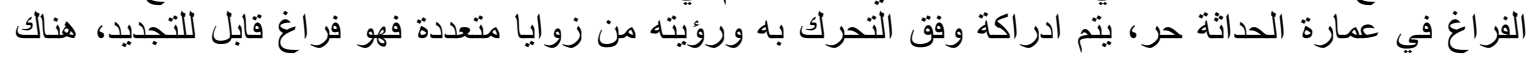

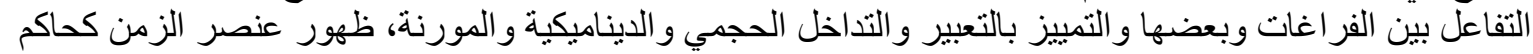

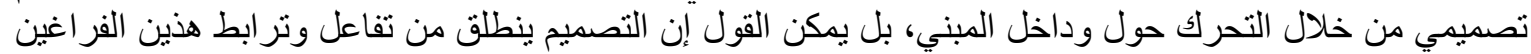

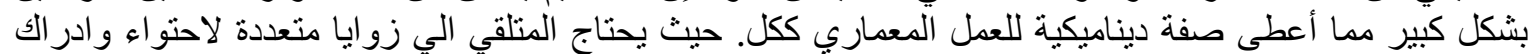

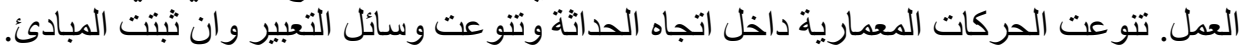

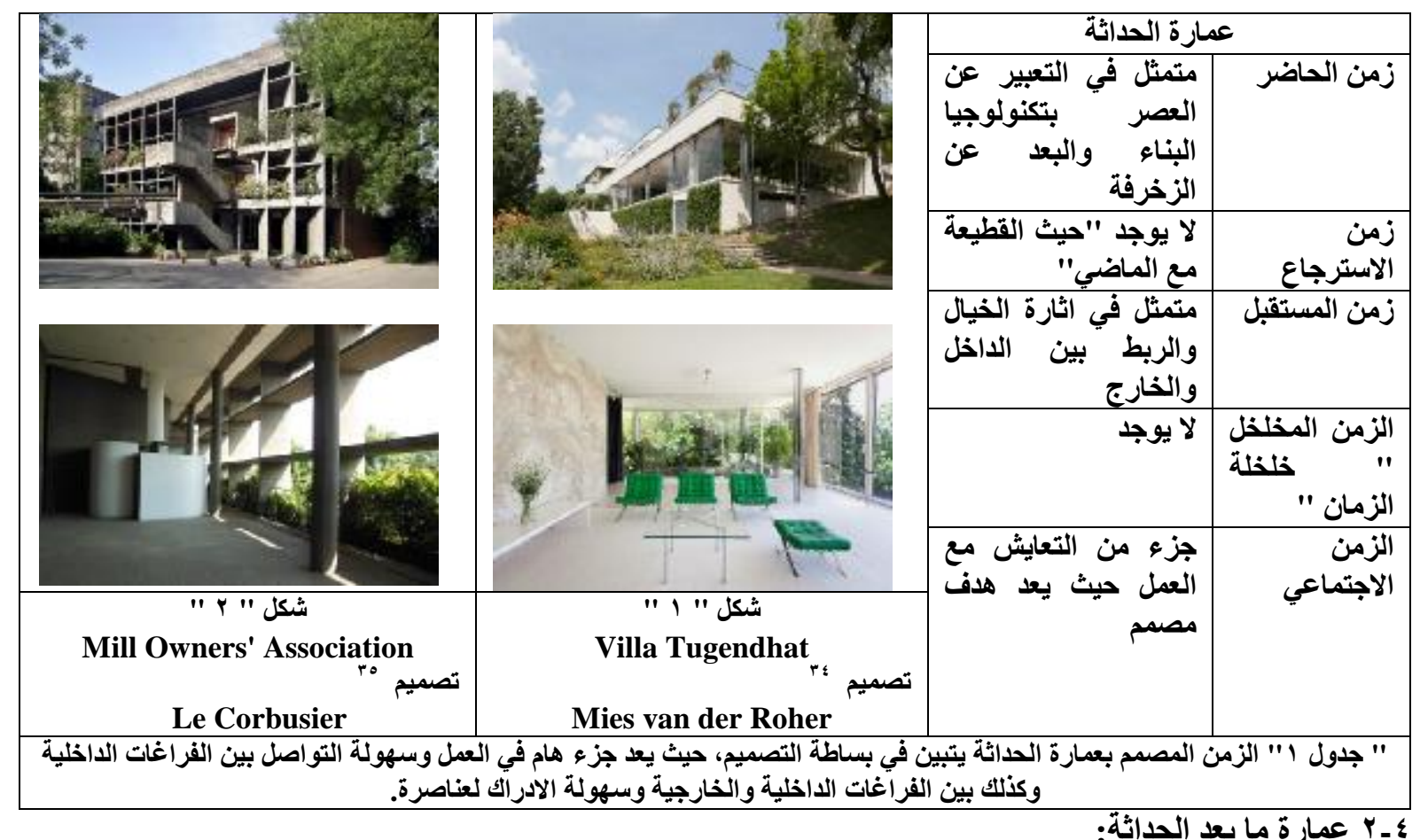

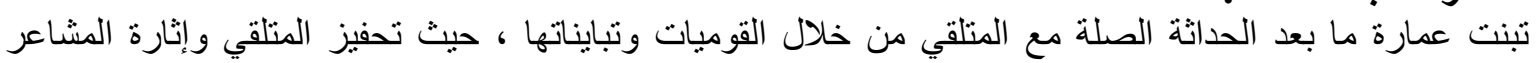

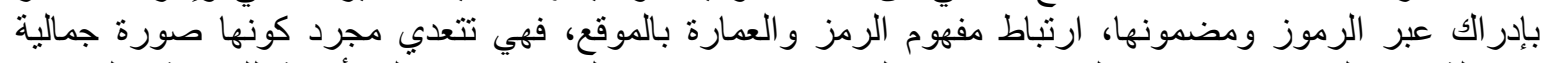

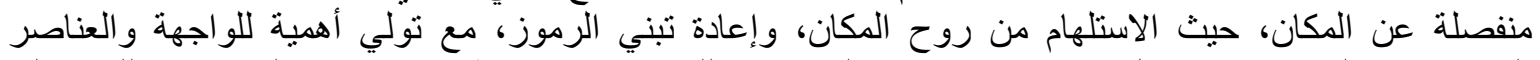

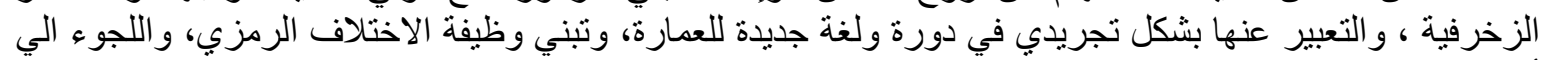

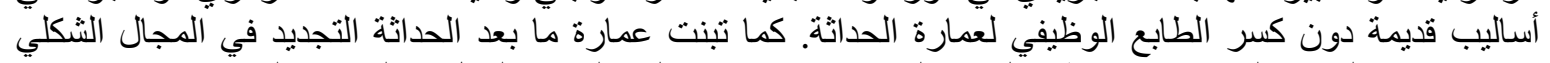

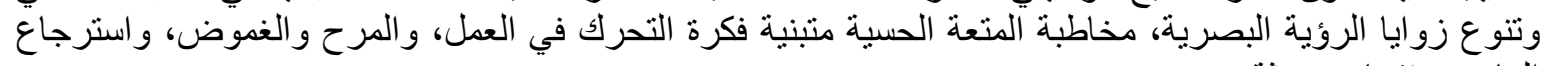
الماضي بتقنيات حديثة. 


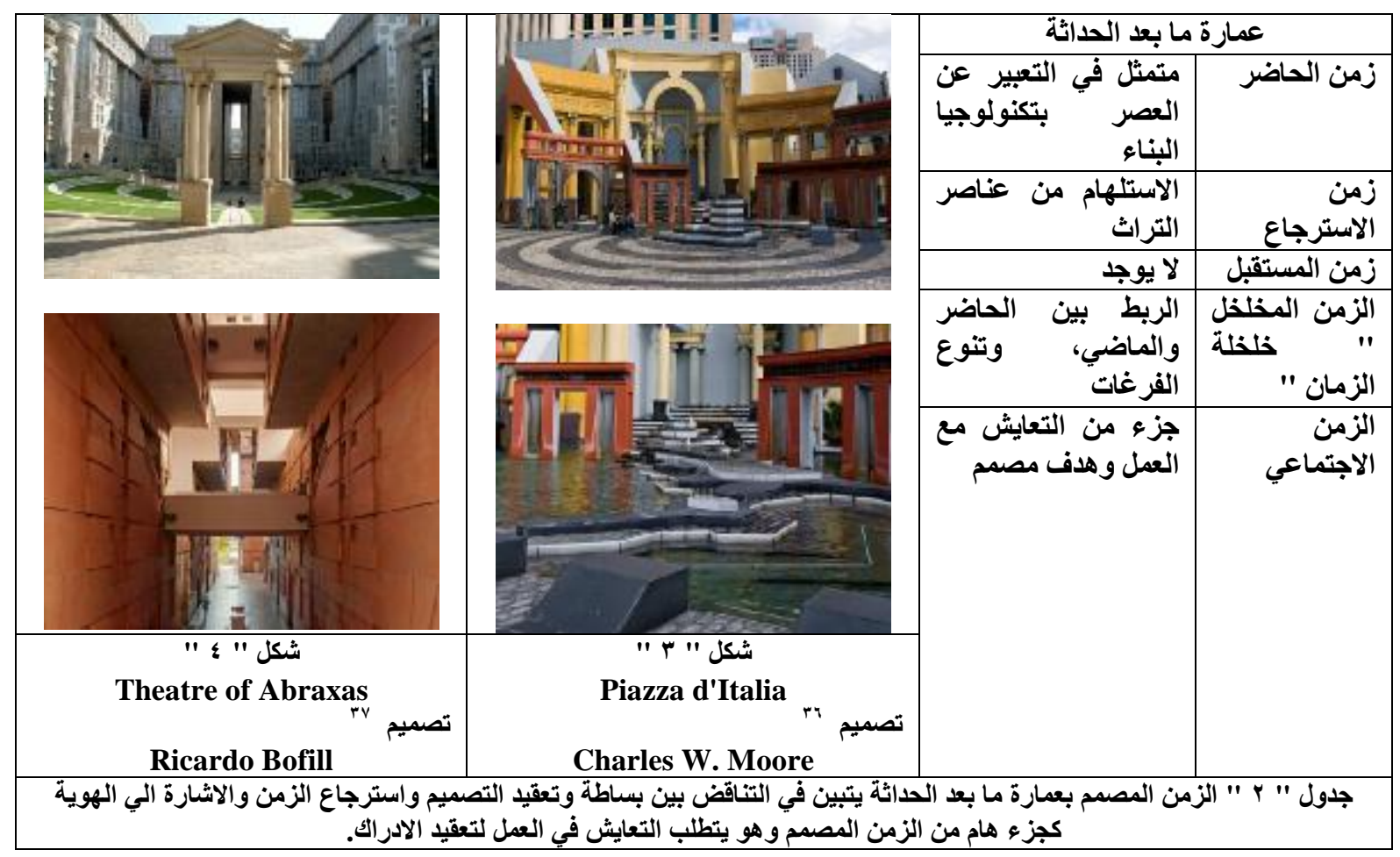

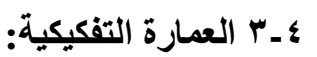

تبنت العمارة التفكيكية تحرير الثنكل من القيود والانتظام ومن ارثباطه بالإشكال التقليدية وتفكيك المبني الي فراغات

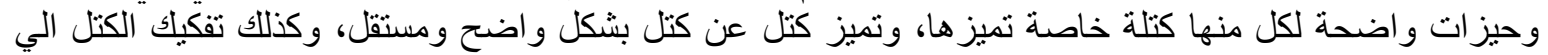

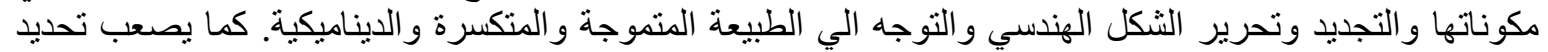

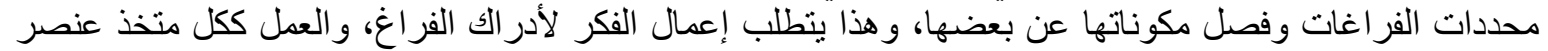

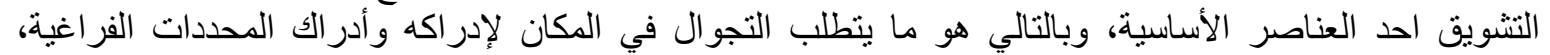

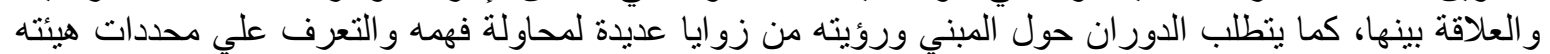

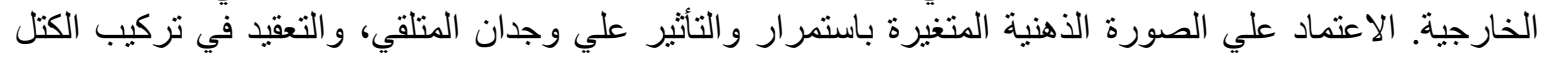

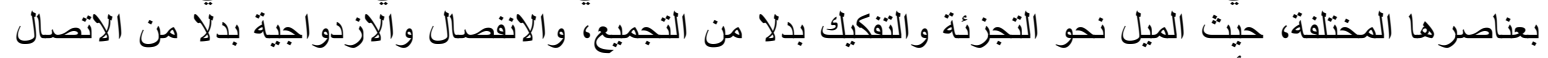
و الاستمر ارية، وتجلت أهداف الديناميكية و الحركة و التطور . تقديم تصور ات مختلفئة ولفئ وغير منوقعة للفر اغات.

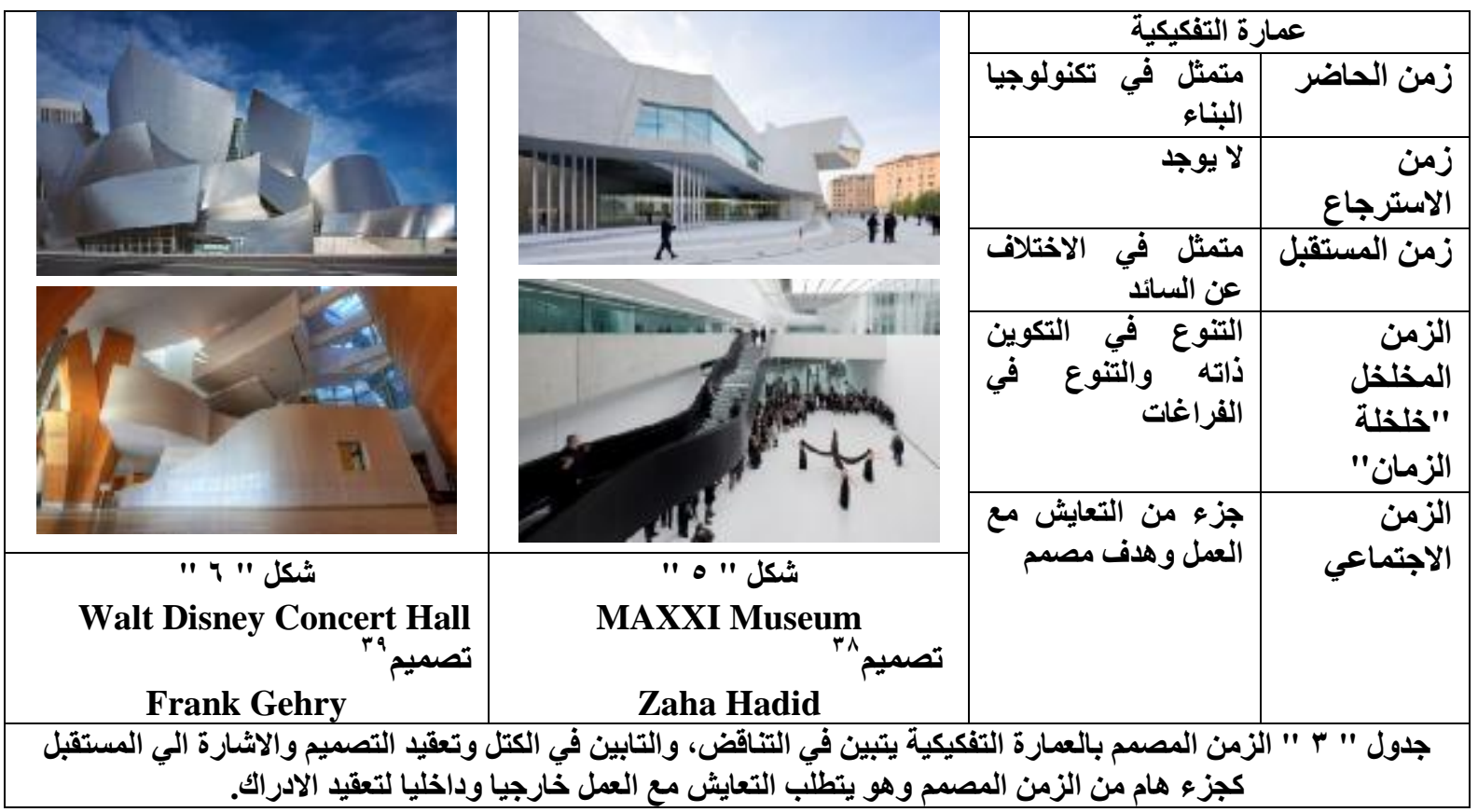




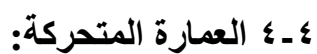

حيث المبني ككل او الحدة الحد عناصرة يمكن ان يتحرك، ويمكن ان تكون الحركة حول محور دوران، وينولا عن ذلك

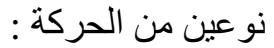

- منفصلة الحركة وفيها يكون كل جزء أو او طابق مسؤل عن حركته.

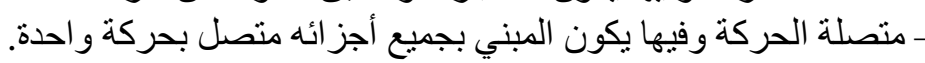

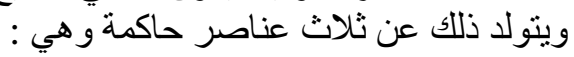

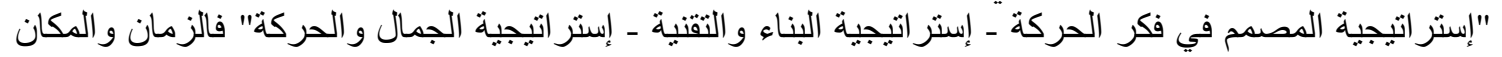

مطلقان بالمعني الفلسفي، نسبيا بالمعني الفيزيائي، تعبيريان بالمعني المعنية المعاري.

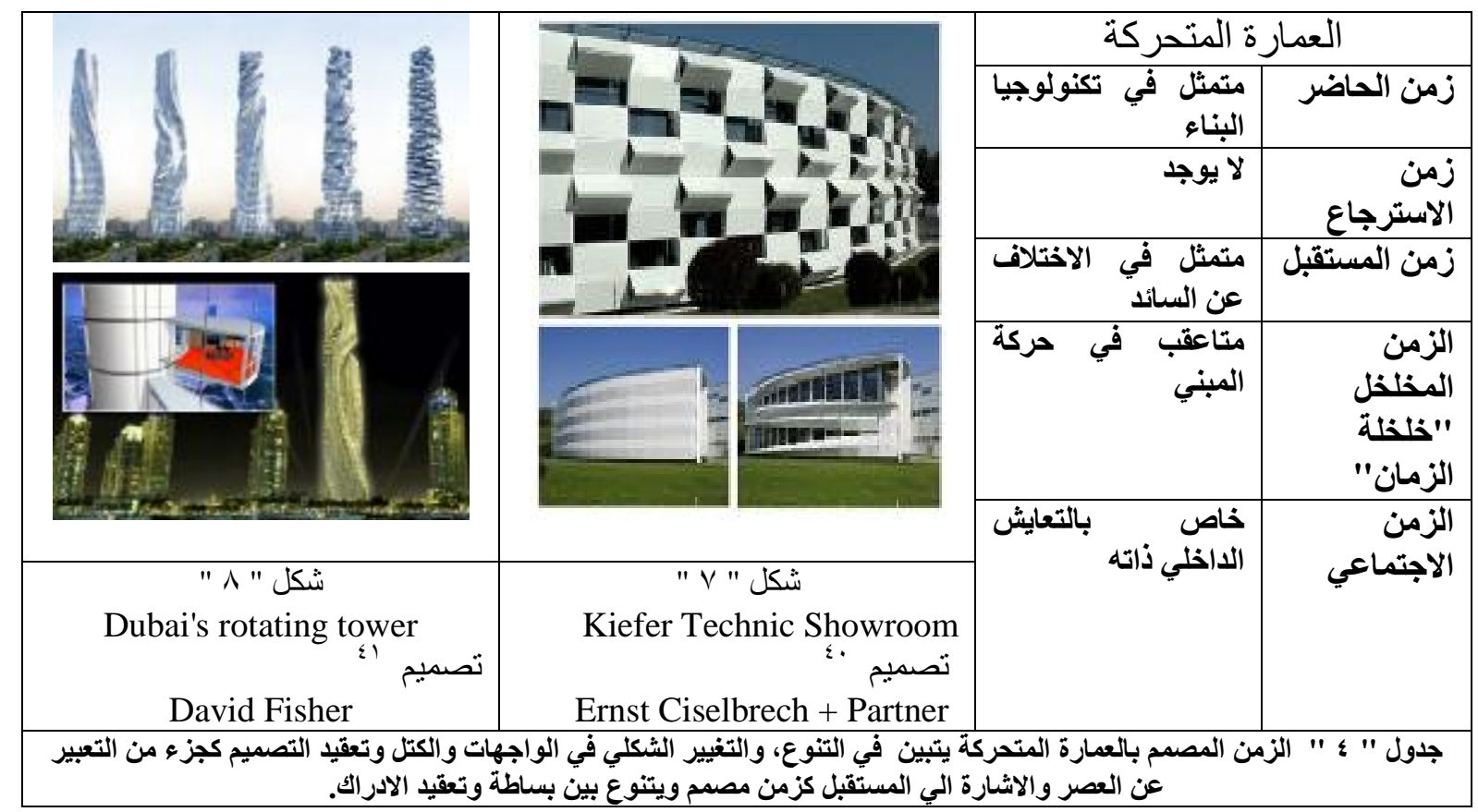

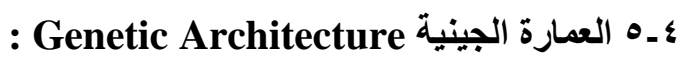

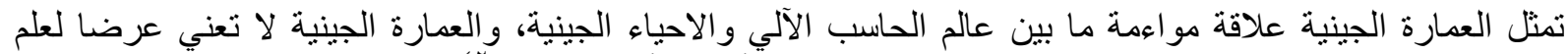

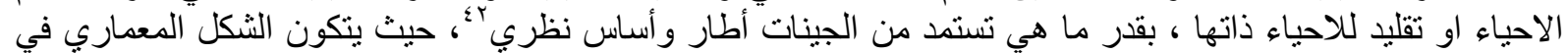

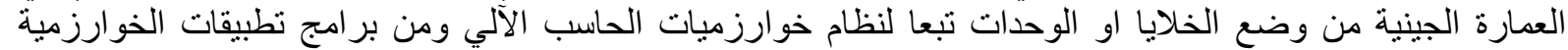

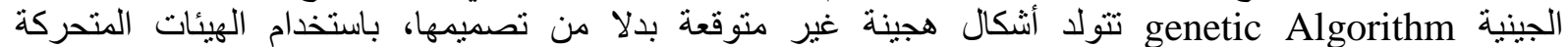
Dynamical Features

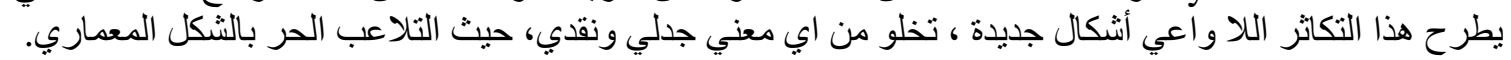




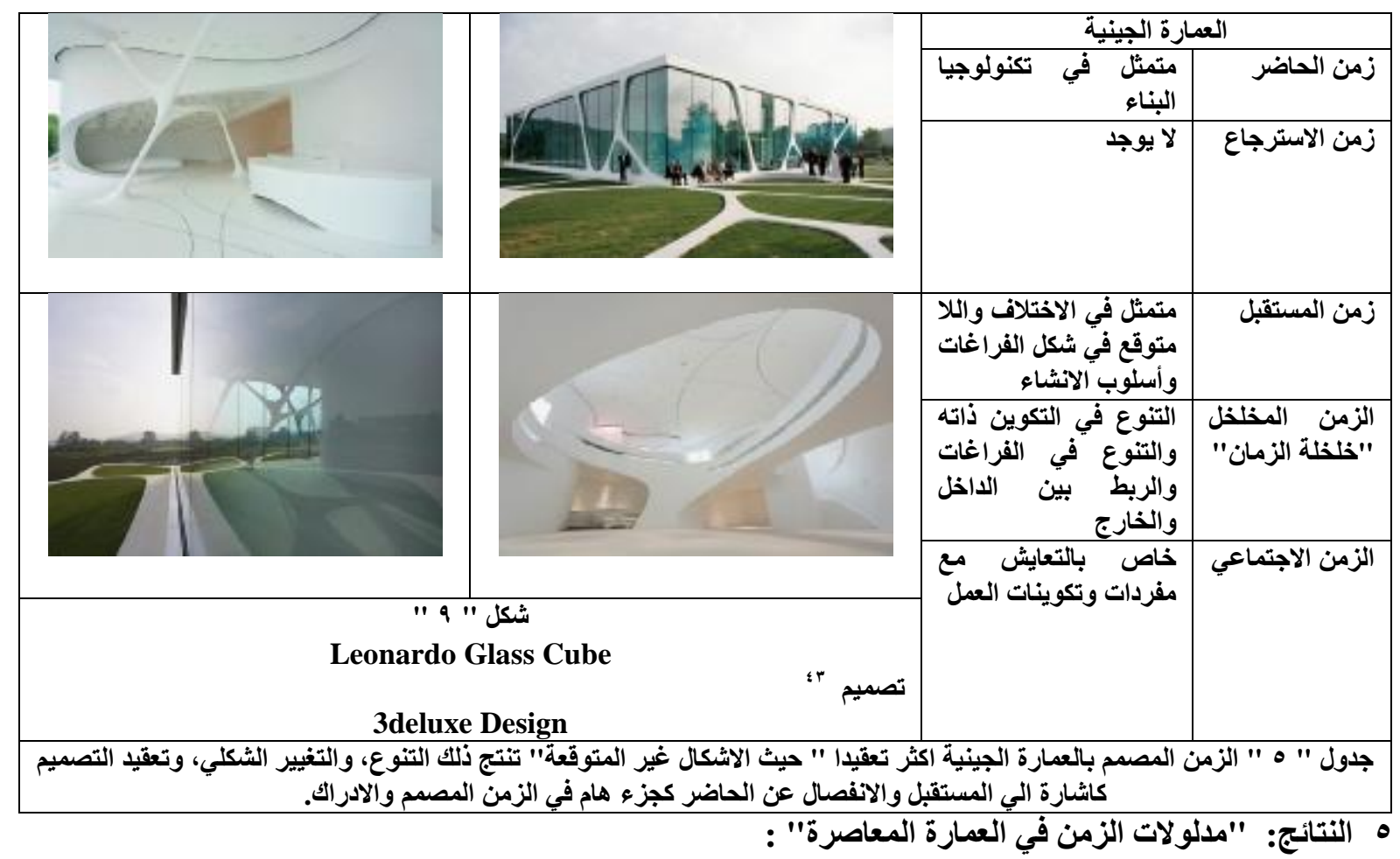

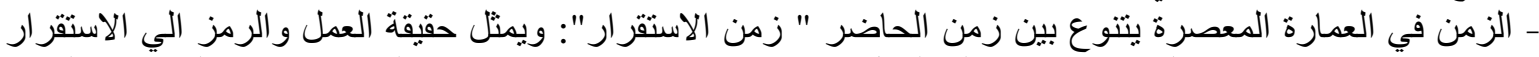

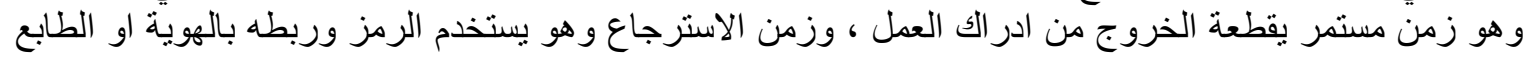

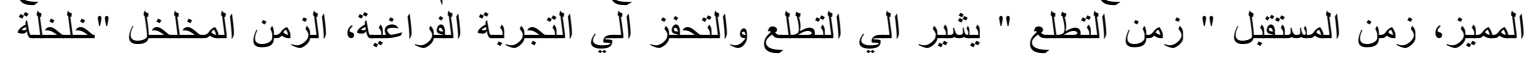

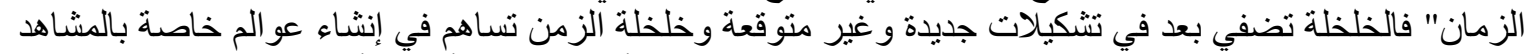

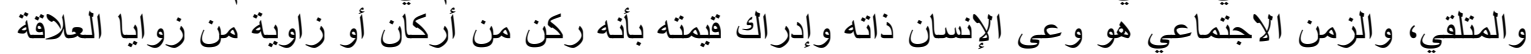

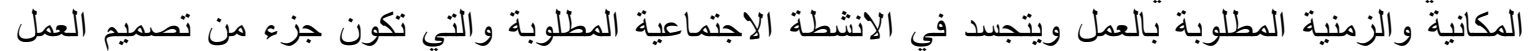

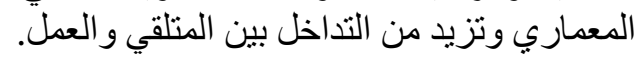

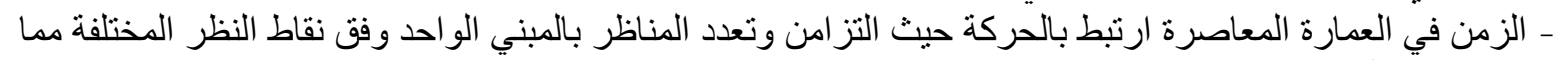

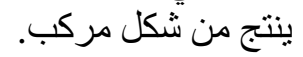

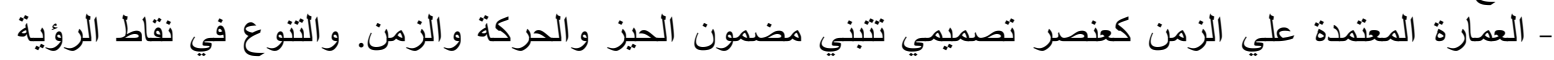

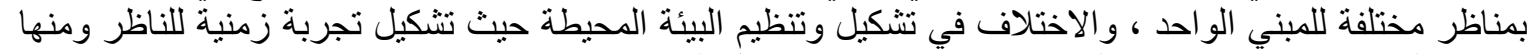

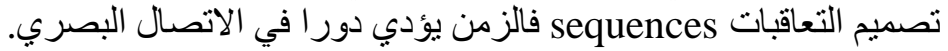
- حركة المشاهد وسر عنه عاملين مهمين في الحيز، ووفق التئنيم التيم ألزماني حيث الثكل المركب الذي يوحي بالحركة

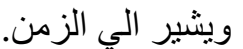
ـ المسار ات كبعد زمني حركي "مسار محدد ضمن خن خطوط تصميم معينة - خلق مشاهد متنو عة مقسمة وفق مسار تحدد

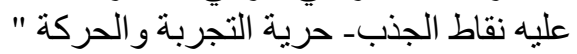

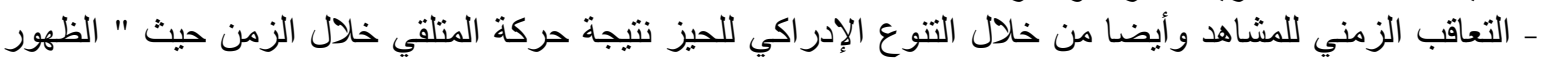

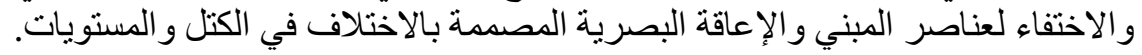

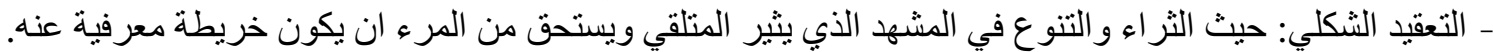

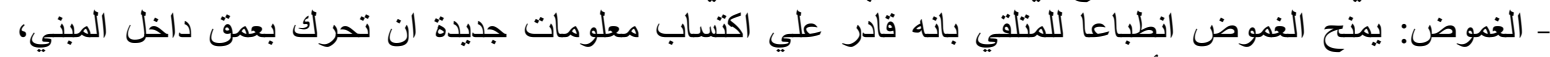

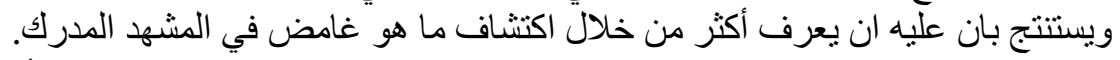

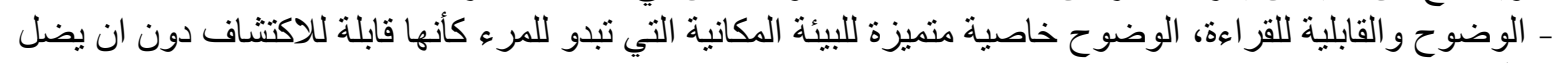

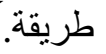
ـ تزويد العمل بعناصر و أثكال لا يمكن للمتلقي إدر اكها "استيعابها" مباشرة من المشاهدة الأولي وبهذا تكون هنالك دائما

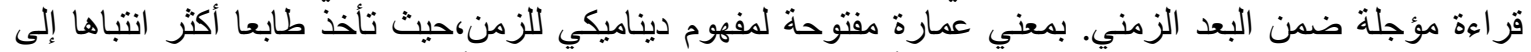

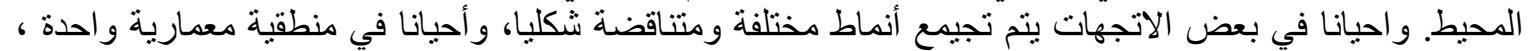
واحيانا تأخذ بالاعتبار التقاليد الثقافية المحلية. وأحيانا يبدو أن لها لغات مستقلة تماما. 
ـ الإمكانيات الهائلة التي نتيحها التكنولوجيا الحديثة توفر السيناريو هات المتتو عة التي تعتمد علي التجربة الادر اكية.

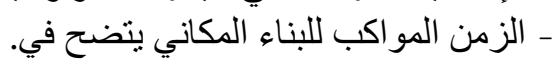

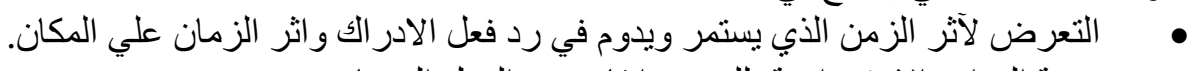

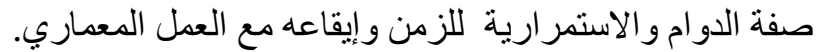

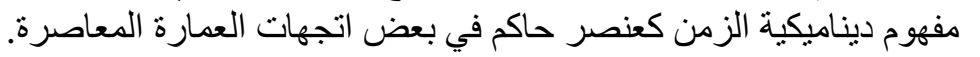

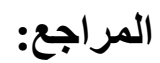

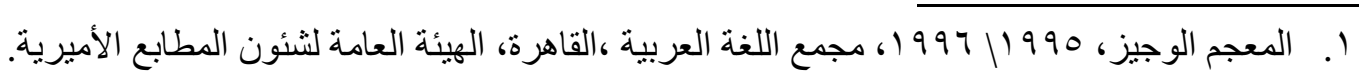

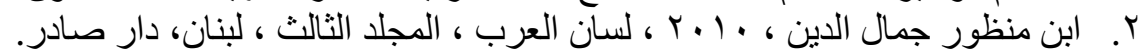

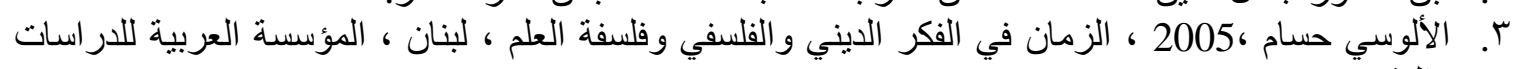

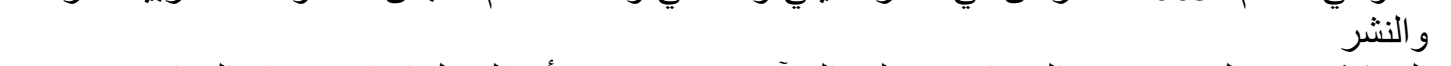
ع. . الزركثي بدر الدين محمد ـ البرهان في علوم القرآن ـ تحقيق محمد أبو الفضل إبر اهيم ـ دار المعارف ـ مصر 1957

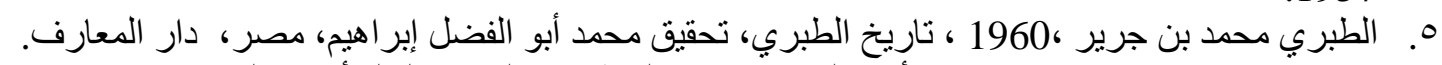

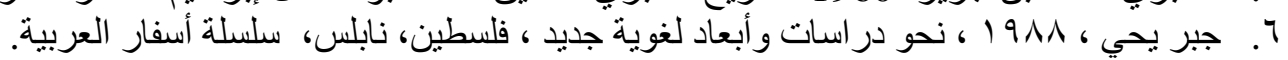

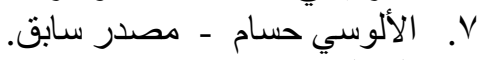

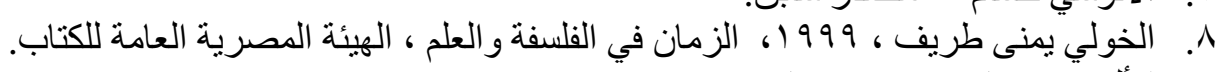

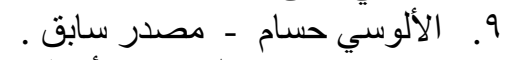

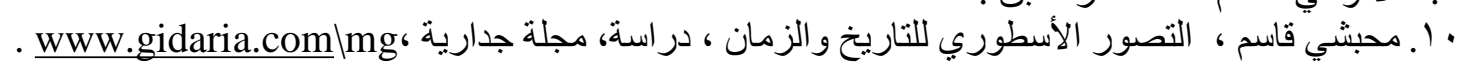
1ا. مطر اميرة ، .91 ا، دراسات في الفلسفة اليونانية " التأمل , الزمان , الوعي "،مصر، دار الثقافة للطباعة والنشر.

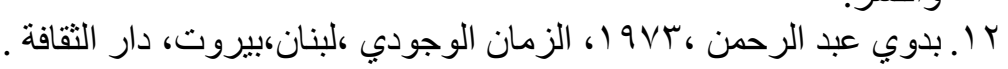
13. Metz Christian, 1974, Language and Cinema (Approaches to Semiotics) ،Mouton de Gruyter.

ـ ا ـ كاسيرر رنست ، (19 19، مدخل إلى فلسفة الحضارة الإنسانية أو مقال في الإنسان ، ترجمة: إحسان عباس،لبنان، دار الأندلس.

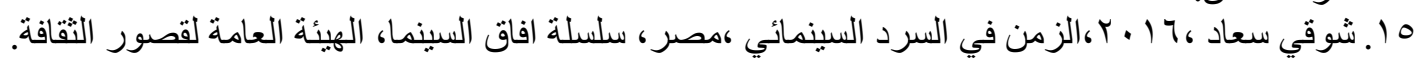

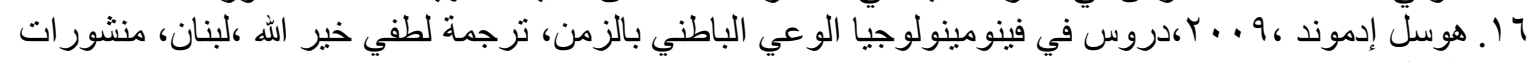

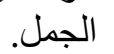

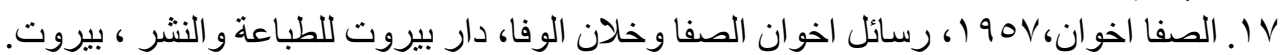

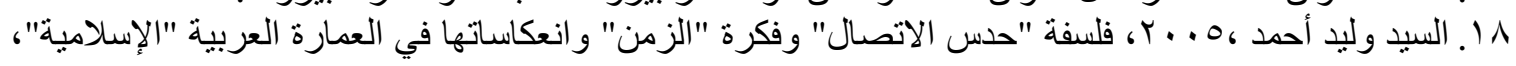
http://www.cpas-egypt.com/pdf/Walid\%20Elsayed/2Articles/025.pdf . . . . 19 ا وابن منظور جمال الدين- مرجع سابق.

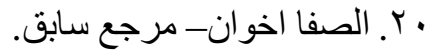

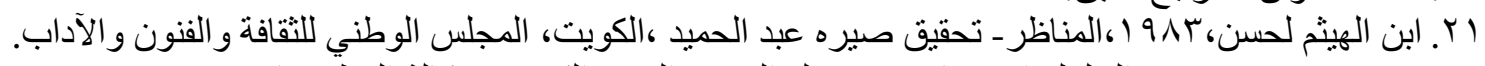

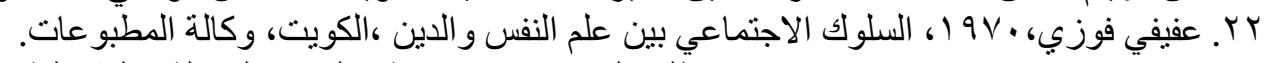

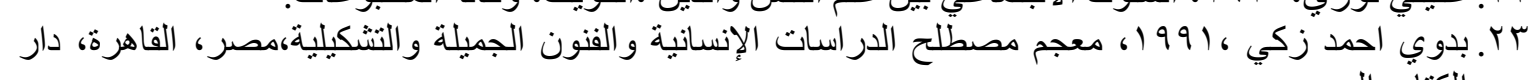

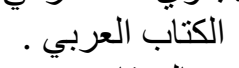

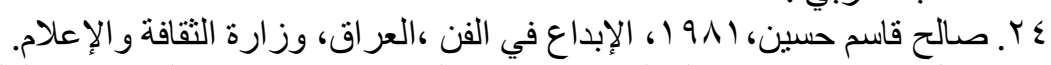

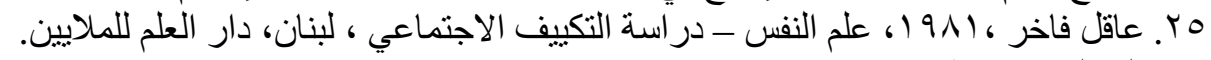

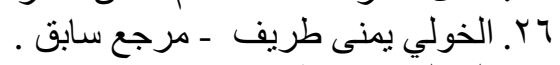
P TV

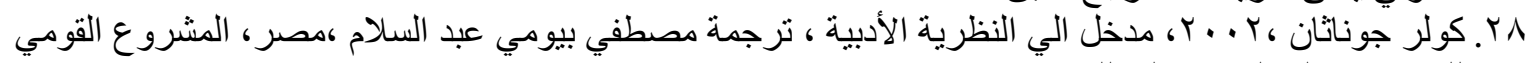

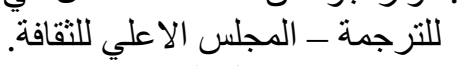

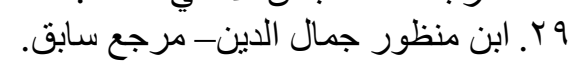

30. Jencks Charles ,1980, Late Modern Architecture,Academy editions.

$$
\text { ا ب. المعجم الوجيز - مرجع سابق. }
$$


32. Gurevich, A.J., (1976), Time as a problem of cultural history, In L. Gardet, A. J. Gurevich, A. Kagame, C. Larre, G. E. R. Lloyd, A. Neher, A. Panikkar, G. Pattaro, \& P. Ricoeur (Eds.), Cultures and time, Paris: UNESCO Press. J. Gurevich

33. Gardet In Louis , 1976, Cultures and Time. Unesco Press.

34. Lurcat Andre,1957, Formes Composition Et Lois D'Harmonie, Elements d' une Science de L'Esthetique Architecturale- Livre 5, Paris, Editions Vincent- FRal\& Cie.

35. https://www.archdaily.com/157555/ad-classics-villa-tugendhat-mies-van-der-rohe

36. https://www.archdaily.com/464142/ad-classics-mill-owners-association-building-lecorbusier

37. https://scenographix.smugmug.com/Architecture/Piazza-dItalia-New-Orleans

38. http://www.ricardobofill.com/projects/les-espaces-dabraxas

39. h ps://www.archdaily.com/43822/maxxi-museum-zaha-hadid-architects

40. 39https://www.archdaily.com/441358/ad-classics-walt-disney-concert-hall-frankgehry

41. http://ming3d.com/wordpress/?p=815

42. https://archinect.com/news/article/147271957/taking-your-pad-for-a-spin-dubai-srotating-tower-proposal-is-back.

43. Stiny George Nicholas ,1985, genetic computation Computing with Form and Meaning in Architecture, Journal of Architectural Education- Blackwell Publishing on behalf of the Association of Collegiate Schools of Architecture.

44. khhttps://archello.com/project/leonardo-glass-cube-2 